\title{
?1
}

TI 2019-033/V

Tinbergen Institute Discussion Paper

\section{Premature Deindustrialization through The Lens of Occupations: Which Jobs, Why, and Where?}

\section{Revision: December 30, 2020}

\section{David Kunst ${ }^{1}$}

\footnotetext{
${ }^{1}$ Tinbergen Institute and Vrije Universiteit Amsterdam, School of Business and Economics, Department of Economics
} 
Tinbergen Institute is the graduate school and research institute in economics of Erasmus University Rotterdam, the University of Amsterdam and VU University Amsterdam.

Contact: discussionpapers@tinbergen.nl

More TI discussion papers can be downloaded at https://www.tinbergen.nl

Tinbergen Institute has two locations:

Tinbergen Institute Amsterdam

Gustav Mahlerplein 117

1082 MS Amsterdam

The Netherlands

Tel.: +31(0)205984580

Tinbergen Institute Rotterdam

Burg. Oudlaan 50

3062 PA Rotterdam

The Netherlands

Tel.: +31(0)10408 8900 


\title{
Premature Deindustrialization through the Lens of Occupations:
}

\section{Which Jobs, Why, and Where?}

\author{
David Kunst \\ Contact: david.m.kunst@gmail.com.
}

December 30, 2020

\begin{abstract}
A growing literature documents that deindustrialization has often set in at historically low levels of income in recent decades. However, there is little evidence on which kind of jobs are disappearing prematurely, and some debate on whether the phenomenon is transitory or structural. Using a new data set on manufacturing employment by occupation, this article makes four propositions about 'premature deindustrialization': First and second, the disappearing jobs have been among the least skilled, yet most formal. Third, they are considered to be vulnerable to automation by ICT. Fourth, the phenomenon pertains most clearly to high and middle income countries, as low income countries have been spared from premature job losses. Overall, the employment patterns are consistent with a pervasive shift of the 'automation frontier' separating tasks that are automated from those which are not, and suggest a structural decrease in the ability of manufacturing to employ unskilled labor productively.
\end{abstract}

JEL: O14, O17, O33, J23, F63

Keywords: Manufacturing, Deindustrialization, Structural transformation, Globalization, Formality of employment 


\section{Introduction}

Manufacturing has long been considered a quintessential stepping stone on the development ladder due to its ability to employ unskilled workers productively (Lewis, 1954). Reallocating workers from agriculture to manufacturing promises large gains in economy-wide productivity, and structural transformation-fuelled growth can take place even if 'fundamentals' such as educational attainments lag behind (Rodrik, 2013a). Moreover, Rodrik (2013b) finds that unlike other industries, manufacturing exhibits unconditional convergence in labor productivity, which makes it a potential driver of convergence in living standards across countries. However, a growing literature documents that developing countries have been running out of manufacturing employment opportunities earlier and at much lower levels of income in recent decades, compared to the experience of early industrializers (Rowthorn and Coutts, 2004 Dasgupta and Singh, 2006 Amirapu and Subramanian, 2015; Rodrik, 2016, Felipe et al. 2018). This raises the question to what degree manufacturing is still able to play its traditional role in economic development.

Existing studies of premature deindustrialization focus on aggregate manufacturing employment, which leaves open the question what kind of jobs have disappeared 'prematurely'. In particular, is it jobs that unskilled workers from the countryside may previously have been able to take up? Moreover, many of the benefits ascribed to manufacturing pertain in particular to formal manufacturing, whereas La Porta and Shleifer (2008) paint a rather bleak picture of wages and productivity in informal manufacturing firms. Hence, the consequences of premature deindustrialization for development prospects hinge on whether it is mostly formal or informal manufacturing jobs that have disappeared. A better characterization of the disappearing jobs also helps to clarify in what sense the normative flavor of the term 'premature deindustrialization' is warranted.

Second, there is some debate about the main drivers of the phenomenon: while Rodrik (2016) and Felipe et al. (2018) assign a prominent role to labor-saving technological progress, Haraguchi et al. (2017) argue that developing countries' difficulties are entirely due to globalization- and more specifically, due to the entry of China into the world market, with its strong comparative advantage in manufacturing Moreover, the

\footnotetext{
${ }^{1}$ This makes Haraguchi et al. (2017) considerably more optimistic about the future prospects for manufacturing-led growth in developing countries: 'After its success in labor intensive industries, China is likely to upgrade its industrial structure following the path of high-income countries. Once this happens, there may be greater opportunities for current low-income countries to pursue manufacturing activities; manufacturing would then perhaps become more, not less, important for them. Thus, the recommendation for developing countries is to not turn away from manufacturing and abandon the path of economic
} 
recent increases in manufacturing employment in some lower income countries such as Vietnam or Cambodia raise questions about the generality of the phenomenon of premature job losses.

From the perspective of the task literature initiated by Autor et al. (2003), a testable implication of the technological change-based explanations is a reduction in labor demand in particular for the production tasks that have only recently become automatable (as opposed to manufacturing employment across the board). While finding such a 'task-biased' labor demand trend would not necessarily imply that premature deindustrialization has been entirely driven by technological change, it would provide evidence against the argument that the phenomenon is entirely due to China's size and comparative advantage, and does not also reflect the adoption of labor-saving technologies within developing countries. However, such an assessment requires moving beyond aggregate manufacturing employment.

To address these questions, I analyze trends in manufacturing employment by occupation in 125 countries for multiple years between 1960 and 2014, obtained from harmonized household surveys. While the sample is imbalanced, country coverage goes significantly beyond the 42 countries in Rodrik (2016) and the 62 countries in Felipe et al. (2018), and the sample includes a greater number of poorer developing countries in particular. A subset of the surveys also includes data on education, wages, and the formality of employment. Analyzing employment trends in manufacturing from the perspective of occupations is insightful because occupations differ along three dimensions that are relevant to the open questions: they require different levels of skill, differ in their typical level of formality of employment, and also differ in their intensity in tasks that are suitable to automation by information and communications technology (ICT).

Drawing on the survey data, I make four propositions about premature deindustrialization: first, it is mostly unskilled jobs that have disappeared prematurely, and also the wage premium of workers with little formal education in manufacturing, relative to other industries, has declined. By contrast, medium skilled craftsman occupations have always been responsible for the tapering off of manufacturing employment at high enough levels of GDP per capita, and the data do not suggest any change in that respect when comparing the pre- and post-1990 period. Second, the disappearing jobs tend to be formal-both relative to the overall labor market, and to the manufacturing average. Third, it is driven by occupations which are intensive in tasks that are that are suitable to automation by ICT. And finally, it has to date been a high and middle years' (p. 307). 
income country-phenomenon, as low income countries have been spared from premature job losses.

Taken together, these propositions advance our understanding of the future of manufacturing-led growth in developing counties by painting a nuanced picture: on the one hand, there is still some scope for employment industrialization in low income countries, facilitated by open goods and capital markets. On the other hand, the induced technology transfer has markedly reduced manufacturing employment opportunities already in countries with intermediate income levels in comparison with previous industrialization patterns. The occupations accounting for the bulk of these employment losses tend to provide low skilled yet formal employment, suggesting that manufacturing is losing its historical ability to provide more secure and productive employment to unskilled workers than other industries in such countries:2

In the next Section, I present my data and look for evidence of premature deindustrialization separately by occupation: essentially, I compare the results from regressing manufacturing employment shares by occupation on country fixed effects and ln GDP per capita-including an interaction of ln GDP per capita with a time-dummy for the later part of my sample period, in order to identify which occupations account for the 'premature' losses in aggregate manufacturing employment. Section 3 presents the four propositions about premature deindustrialization, drawing on the trends in the occupational employment structure and additional survey evidence. Section 4 offers an interpretation of my findings.

\section{Premature Deindustrialization Through the Lens of Occupations}

Existing studies of premature deindustrialization rely on data sources that do not distinguish between different groups of manufacturing workers ${ }^{3}$ To address this gap, I combine census and survey data from the 'Integrated Public Use Microdata Series' (IPUMS), provided by the Minnesota Population Center (2018),

\footnotetext{
${ }^{2}$ See Rodrik (2013a) for a discussion of evidence that for unskilled labor released from agriculture in the process of structural transformation, the main alternative to manufacturing employment in recent decades has been employment in low-productivity services, with limited impact on economy-wide productivity.

${ }^{3}$ They use data from either the UN National Accounts Main Aggregates Database, the Groningen Growth or Development Center (Timmer et al. 2015a), or the database on manufacturing employment for 63 countries assembled by Felipe et al. (2018) from various sources. The UN data and the data set by Felipe et al. (2018) go back to 1970, whereas the Timmer et al. (2015a) data set includes only 42 countries, but goes back to the late 1940s/ early 1950s for many of them. Rodrik (2016) does present evidence of a recent reduction in the demand for unskilled workers in the manufacturing industries of the countries represented in the 'World Input Output Database' by Timmer et al. (2015b) (see Section 3 for a more detailed discussion). However, the countries in this sample are mostly high income countries, and the data start only in 1995 . Hence, this result cannot easily be compared to his finding of premature deindustrialization in developing countries when comparing the pre-1990 to the post-1990 period.
} 
with survey data from the 'International Income Distribution Database' (I2D2). I2D2 is a collection of harmonized and nationally representative household surveys introduced by Montenegro and Hirn (2009) and maintained by the World Bank $t^{4}$ Census and other survey data have the additional advantage that they tend to have more complete coverage of informal employment than national accounts data (McMillan et al. 2014).

The resulting data set contains the distribution of manufacturing employment across the nine major occupation groups of the 'International Standard Classification of Occupations' (ISCO) for 980 country-year observations from 148 countries between 1960 and 2016. I add data on GDP in 2011 international dollar and population from the Penn World Table (Feenstra et al. 2015$)$ to obtain my main analysis sample: it contains data on employment and income from 125 countries, accounting for 91 percent of the world population in 2014, for at least two years between 1960 and 2014 (with an average of 7.4 years per country, and an average spread of 19 years between the first and the last survey). Appendix Adescribes the sample construction and coverage in more detail.

To examine how the manufacturing employment share of a country typically varies with income, column (1) of Table 1 regresses it on ln GDP per capita and its square, ln population and its square, decade dummies and country fixed effects (corresponding to the specification in Rodrik (2016)). The population terms control for the size of the home market (although results are not sensitive to omitting them), and the country fixed effects control for differences in time invariant differences between countries, for instance related to geography. The results confirm Rodrik's finding that aggregate manufacturing employment exhibits a significant inverse U-shape in income, using a different data source.

In Table 2. I test for a tendency of total manufacturing employment to decline 'prematurely' in recent decades by replacing the decade dummies with a dummy variable taking a value of one for surveys from the period after 1990 and its interactions with the ln GDP per capita-terms 5 Column (1) shows that the humpshaped relationship between manufacturing employment and income is driven by the post-1990 observations, as the GDP per capita-terms without post 1990-interactions are jointly insignificant ( $\mathrm{p}$-value=0.21). For a

\footnotetext{
${ }^{4}$ I2D2 is currently not openly available to researchers outside the World Bank. I am grateful to Kathleen G. Beegle, Claudio E. Montenegro, David Newhouse and Aditi Mishra for making these data available to me.

${ }^{5}$ As Rodrik writes, using the 1990 year as a break-point is somewhat arbitrary-but it ensures a sufficient number of observations on either side, and is also useful as a demarcation of the period in which globalization and the adoption of ICT gathered speed.
} 
visual representation, Figure 1 plots the corresponding fitted employment share for a 'typical' country with median population and average country fixed effects against income, both with and without taking into account the post 1990-interactions: while the predicted peak employment share is close to 16 percent in both periods, the estimated GDP per capita level at the peak of manufacturing employment declines substantially,

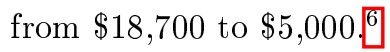

Next, I move beyond the previous literature by distinguishing between five sub-groups of manufacturing workers, which allow for a refined perspective on the phenomenon of premature deindustrialization: 'elementary occupations', 'machine operators', 'craftsmen' and 'clerks' correspond directly to ISCO major groups, whereas 'professionals' subsume ISCO major groups 1-3] These occupations will be characterized in increasing detail throughout the rest of the paper 8 To start with, columns (2)-(6) of Table 1 show how manufacturing employment in these five occupation groups varies with income. Point estimates suggest that employment shares for all of them, except professionals, follow an inverse U-shape.

However, Figure 2 (which again plots the fitted employment shares for a 'typical' country in the sample) highlights that the occupational employment structure varies strongly with income: at low income levels, manufacturing employment consists almost entirely of craftsmen. Craftsman employment in turn peaks already at a GDP per capita around $\$ 3,300$-which is when employment in the other occupations, and

\footnotetext{
${ }^{6}$ In Rodrik (2016), peak manufacturing employment declines from 21.5 to 18.9 percent between both periods, and the income level at which it is reached falls from $\$ 11,000$ to $\$ 4,300$ (in 1990 dollars). Part of the difference to his numbers is explained by the fact that Rodrik does not include the post 1990-dummy also independently in his empirical specification (cf. his Table 9), thereby not allowing for a trend in the share of manufacturing employment between both periods that is unrelated to differences in ln GDP per capita. If I follow him and exclude the independent post-1990 dummy, my estimates of the income level at peak manufacturing employment for both periods are closer to his estimates (namely, they change to $\$ 11,000$ and $\$ 5,100$ respectively, in 2011 dollars), whereas my estimates of the peak manufacturing employment shares remain lower than his (namely, they change to 16.3 and 16.2 percent respectively). This is likely because the 42 countries in his sample include a larger share of relatively industrialized countries (compared to my sample of 125 countries), and because his sample reaches back to the late 1940s / early 1950s (compared to at most 1960 in my sample). With respect to the heterogeneity of premature deindustrialization across occupations documented below, results are similar regardless of whether I omit the independent post 1990-dummy or include it.

${ }^{7}$ And hence, 'managers', 'professionals' and 'technicians and associate professionals'. Occupations in these major groups tend to be intensive in skilled and non-routine tasks, and distinguishing between them reveals no large differences that would be relevant to the arguments made in this paper. Appendix B presents the description of the ISCO major groups by the ILO, which I will introduce in more detail in Section 3

${ }^{8}$ These characterizations will stay at the level of major groups and total manufacturing, since the surveys contain occupation and industry-coding only at the 1-digit level of ISCO and ISIC. However, the 'Occupational Wages Around the World' (OWW) database, described by Freeman and Oostendorp (2020), contains examples from each of these five aggregated occupation groups at the 4-digit level of ISCO, and the 2-digit level if ISIC. For instance, it includes the machine operator occupations 'thread and yarn spinner' and 'cloth weaver (machine)' from the textiles industry, as well as the craftsman occupation 'loom fixer, tuner' and the elementary occupation 'labourer'. The occupations from the printing \& publishing industry include the clerical occupation 'office clerk', and occupations from the chemical industry include the 'chemical engineer'. See Kunst (2019) for more examples at the level of more disaggregated occupations and industries, including detailed task descriptions.
} 
especially of machine operators, tends to grow rapidly. Employment in clerical and elementary occupations peaks at intermediate income levels $(\$ 8,900$ and $\$ 9,100$ respectively), whereas machine operator employment only declines after an income of $\$ 17,000$ has been reached. Employment of manufacturing professionals even increases over the entire observed income range 9

In Section 3 I argue that for the debate about the origins of premature deindustrialization as well as for its labor market consequences, it matters which of these occupations account for the 'premature' employment losses after 1990. To first establish the facts, columns (2)-(6) of Table 2 show that up to 1990, the inverse U-shape of manufacturing employment in income was driven entirely by craftsmen. For this period, there is no statistically or quantitatively important evidence of a non-linear relationship between manufacturing employment and income levels for any of the other four occupation groups. For employment in machine operator, elementary and clerical occupations, the data suggest a significant move towards a U-shape only for the period after 1990, whereas no change is found for craftsmen (U-shape in both periods) or professionals (no U-shape in either period) 10 In summary, the premature deindustrialization in terms of aggregate manufacturing employment shown in column (1) and previously documented in the literature has been driven by machine operator-, elementary- and clerical occupations.

Figure 3 plots the corresponding fitted employment shares by income: it shows that a peak only exists for the post-1990 period for elementary occupations (at $\$ 10,400$ ), machine operators (at $\$ 8,100$ ) and clerks (at $\$ 5,800)$, whereas fitted employment increases almost linearly over the observed income range during the early period. Moreover, the simulated peak employment shares decrease substantially: from 3.4 to 1.6 percent for elementary occupations, 6.9 to 3.9 percent for machine operators, and 2 to 1.3 percent for clerks. By contrast, fitted craftsman and professional employment look very similar for both periods, consistent with the small and insignificant interaction terms in Table 2 "11

\footnotetext{
${ }^{9}$ For an alternative perspective, Appendix Figure C.1 plots the corresponding occupational employment shares after normalizing total manufacturing employment to 100 for every country-year, which facilitates answering the question which of the occupations is most important within manufacturing. As the Figure highlights, the answer to this question strongly depends on a country's income level: in the lowest income countries, more than 80 percent of manufacturing workers tend to be craftsmen, and craftsmen remain important also at intermediate income ranges. At the upper end of observed income levels, professionals are the most important group of manufacturing workers, and the employment share of the other occupations within manufacturing increases most strongly at low and intermediate income levels. See Kunst (2019) for an analysis of labor demand changes within manufacturing since the 1950s.

${ }^{10}$ While these shifts are statistically significant as shown by the joint F-tests in the bottom of Table 2 and quantitatively important as shown in the next paragraph, standard errors are sizeable. This can be explained by the relative scarcity of observations from the period up to 1990, as discussed in Appendix A

${ }^{11}$ Note that in particular for machine operators, a sizeable decline in employment after controlling for GDP per capita is
} 
Appendix Table C.1 presents the results of two robustness checks: first, I exclude about 6 percent of the surveys which do not contain manufacturing observations for all five occupations (resulting in an employment share of zero for the respective occupation). This may indicate that some occupations did not play any role in the respective country and year-but could also hint at issues with the sampling, or the harmonization of the occupation classification. However, results are robust to excluding such surveys. Second, I keep only surveys from the 43 countries for which my sample includes at least one survey for both the period up to and after 1990. Also for this sub-sample, I find a significant shift in the relationship between manufacturing employment and income for total manufacturing as well as elementary, machine operator and clerical occupations, but not for craftsmen and professionals. This suggests that even within the same countries, the relationships between changes in income and manufacturing employment has changed 12

In summary, the evidence robustly suggests that manufacturing employment in elementary-, machine operator- and clerical occupations has disappeared 'prematurely' after 1990, whereas employment in craftsmanand professional occupations did not. In the next Section, I discuss the labor market consequences and origin of these employment trends by making four propositions about premature deindustrialization.

already apparent in the significantly negative decade dummies from Table 1 Following Rodrik (2016), a more direct test for 'premature deindustrialization' is however based on the joint significance of the interactions of the GDP per capita terms the a post-1990 dummy in Table 2

${ }^{12}$ To save space, I present the results from these robustness checks for joint employment in elementary, machine operator and clerical occupations (for which the joint F-tests of the interaction terms in Table 2 indicate a structural break around 1990), and for joint employment in craftsmen and professional occupations (for which they do not). However, results are similar to those for the benchmark sample also when running the regressions separately for all occupations (results available upon request). 


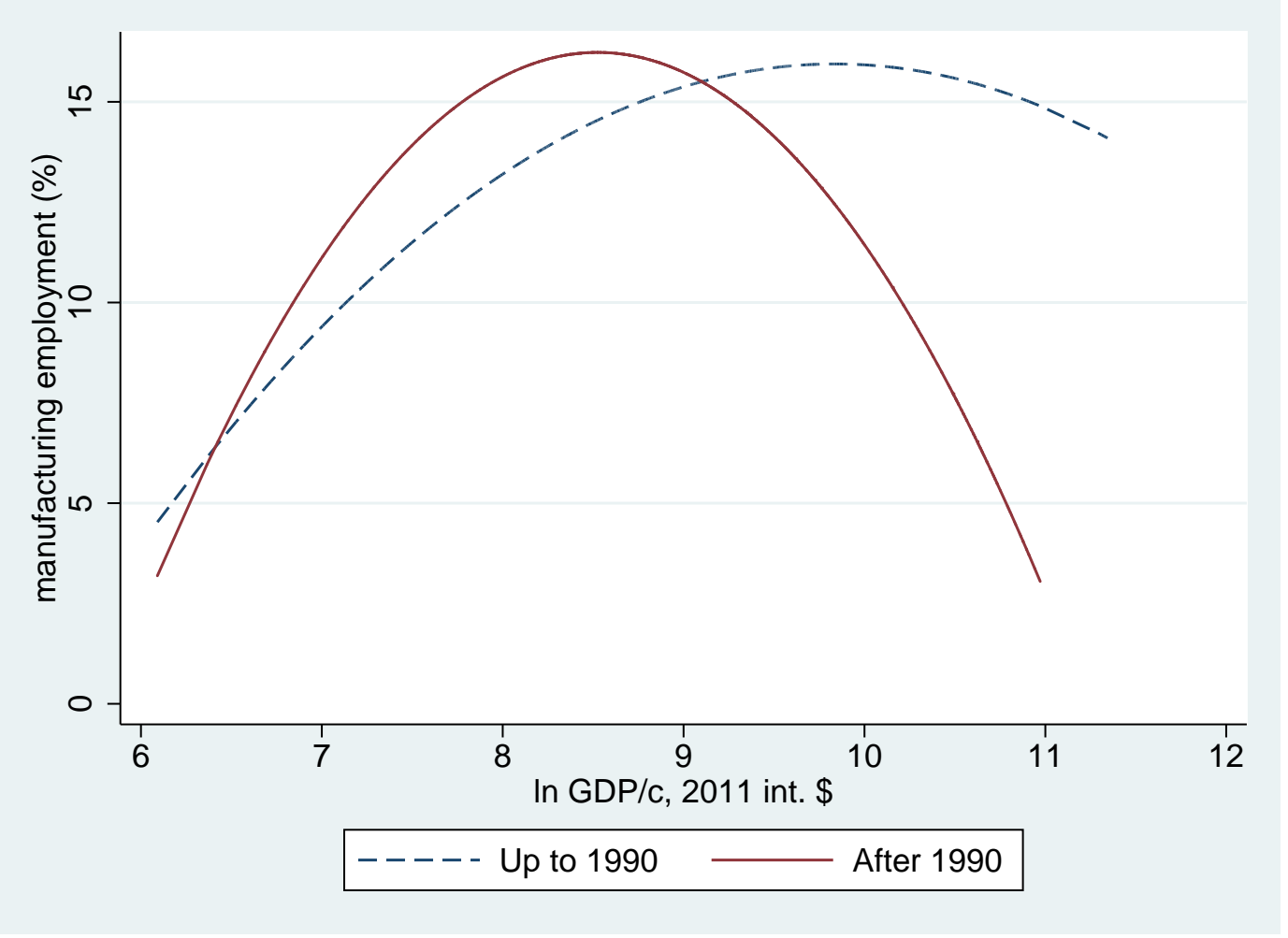

Figure 1: Simulated employment shares for total manufacturing: period up to versus post-1990 The Figure shows the predicted manufacturing employment shares in the periods up to and after 1990 from a regression on ln GDP per capita and its square, a post-1990 dummy and its interactions with the ln GDP per capita-terms, ln population and its square, and country fixed effects. Period and country effects are all averaged and the population size is set to the sample median to obtain the relationship for a 'typical' country in the sample. Column (1) of Table 2 presents the specification. 

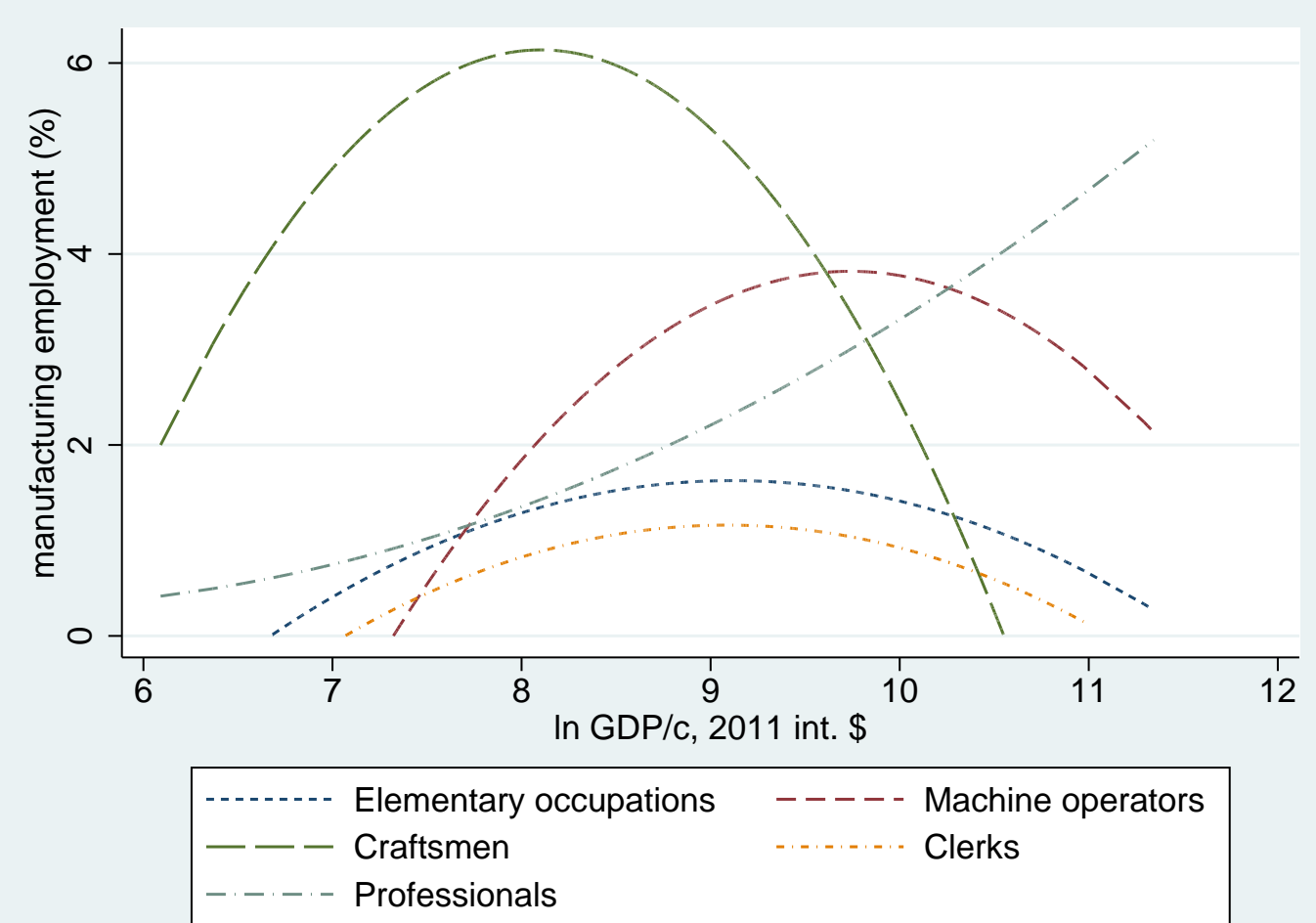

Figure 2: Simulated manufacturing employment in total employment (percentage points) The Figure shows the predicted manufacturing employment shares from a regression on ln GDP per capita and its square, ln population and its square, decade fixed effects and country fixed effects. Period and country effects are all averaged and the population size is set to the sample median to obtain the relationship for a 'typical' country in the sample. Table 1 presents the specifications. 

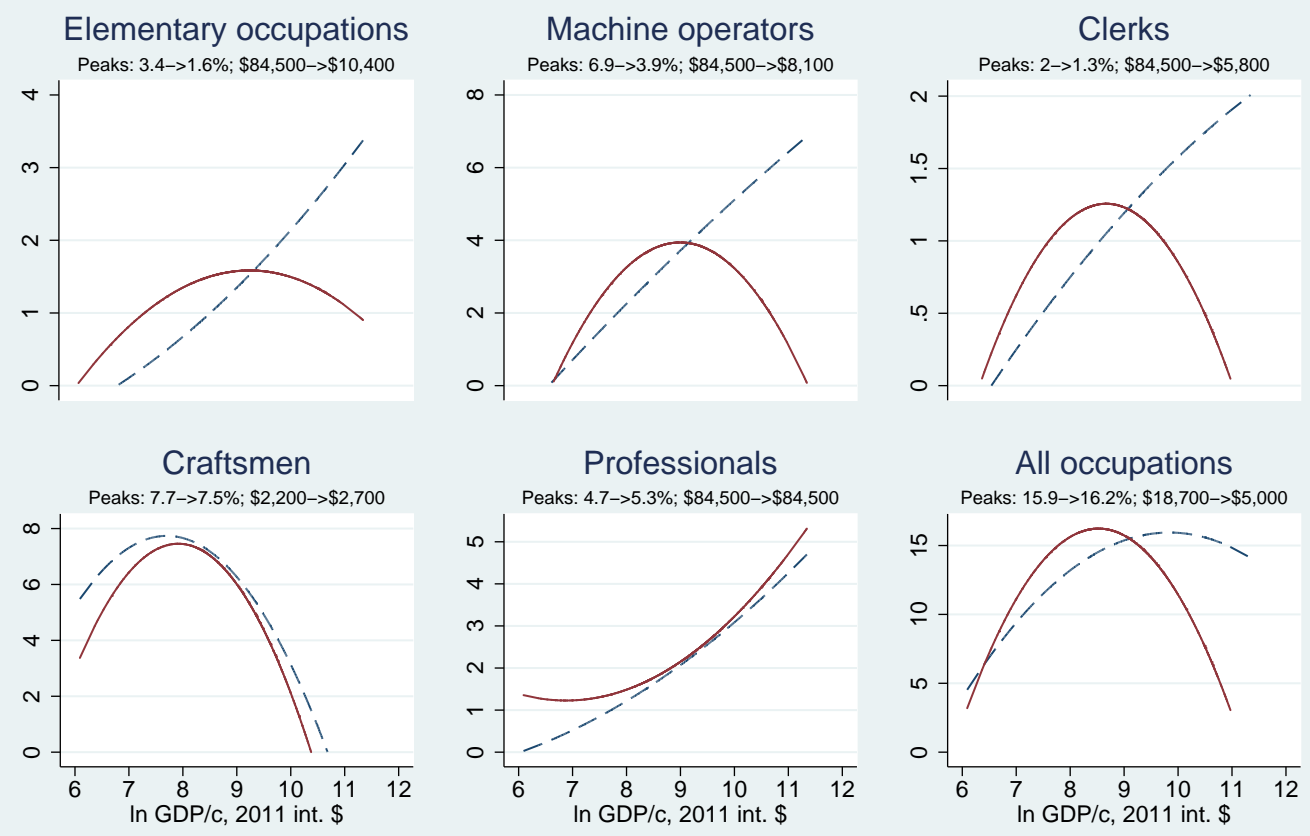

\section{---- - Up to $1990 \quad$ After 1990}

Figure 3: Simulated manufacturing employment shares by occupation: period up to versus post-1990 All simulations are based on the models presented in Table 2 The subtitles of each Figure in the panel indicate the highest simulated employment share in the period up to and after 1990, as well as the estimated GDP per capita levels at which this peak employment is reached. 
Table 1: Manufacturing employment as a function of income

Dependent variable: manufacturing employment in total employment, ages 15-64 (percentage points)

\begin{tabular}{|c|c|c|c|c|c|c|}
\hline & \multirow{3}{*}{$\begin{array}{c}\text { Total } \\
(1)\end{array}$} & \multicolumn{5}{|c|}{ Occupation split } \\
\hline & & $(2)$ & (3) & (4) & $(5)$ & (6) \\
\hline & & Elementary & Operators & Craftsmen & Clerks & Professionals \\
\hline \multirow{2}{*}{$\ln \mathrm{GDP} / \mathrm{c}$} & $41.01^{* *}$ & $4.97^{* *}$ & $12.74^{* *}$ & $16.58^{* *}$ & $5.17^{* *}$ & -1.28 \\
\hline & $(8.08)$ & $(1.72)$ & $(3.97)$ & $(5.58)$ & $(1.20)$ & $(1.27)$ \\
\hline \multirow[t]{2}{*}{ ln GDP/c squared } & $-2.26^{* *}$ & $-0.27^{* *}$ & $-0.65^{* *}$ & $-1.02^{* *}$ & $-0.28^{* *}$ & $0.13^{+}$ \\
\hline & $(0.43)$ & $(0.09)$ & $(0.23)$ & $(0.30)$ & $(0.07)$ & $(0.07)$ \\
\hline \multirow[t]{2}{*}{ ln population } & $5.49^{*}$ & 0.22 & $4.02^{+}$ & 0.18 & 0.54 & 0.16 \\
\hline & $(2.43)$ & $(0.57)$ & $(2.14)$ & $(2.44)$ & $(0.34)$ & $(0.56)$ \\
\hline \multirow[t]{2}{*}{ ln pop. squared } & 0.19 & 0.01 & -0.26 & $0.55^{*}$ & -0.05 & -0.07 \\
\hline & $(0.31)$ & $(0.10)$ & $(0.16)$ & $(0.26)$ & $(0.05)$ & $(0.07)$ \\
\hline \multirow[t]{2}{*}{$1970 \mathrm{~s}$} & $-2.07^{*}$ & $0.41^{+}$ & $-2.78^{*}$ & 0.08 & 0.10 & -0.05 \\
\hline & $(0.99)$ & $(0.23)$ & $(1.33)$ & $(1.02)$ & $(0.15)$ & $(0.19)$ \\
\hline \multirow[t]{2}{*}{$1980 \mathrm{~s}$} & $-3.89^{*}$ & 0.45 & $-3.65^{+}$ & -1.18 & -0.07 & 0.32 \\
\hline & $(1.57)$ & $(0.37)$ & $(1.96)$ & $(1.62)$ & $(0.22)$ & $(0.30)$ \\
\hline \multirow[t]{2}{*}{$1990 \mathrm{~s}$} & $-5.58^{* *}$ & 0.53 & $-4.36^{+}$ & -2.48 & -0.24 & 0.52 \\
\hline & $(1.70)$ & $(0.39)$ & $(2.26)$ & $(1.72)$ & $(0.28)$ & $(0.33)$ \\
\hline \multirow{2}{*}{$2000 \mathrm{~s}$} & $-7.50^{* *}$ & 0.44 & $-5.01^{+}$ & -2.83 & -0.47 & 0.45 \\
\hline & $(2.03)$ & $(0.46)$ & $(2.53)$ & $(1.98)$ & $(0.33)$ & $(0.37)$ \\
\hline \multirow{2}{*}{$2010 \mathrm{~s}$} & $-9.68^{* *}$ & 0.38 & $-5.80^{*}$ & $-3.59^{+}$ & $-0.67^{+}$ & 0.23 \\
\hline & $(2.23)$ & $(0.52)$ & $(2.73)$ & $(2.14)$ & $(0.36)$ & $(0.43)$ \\
\hline$R^{2}$ & 0.259 & 0.031 & 0.136 & 0.181 & 0.185 & 0.142 \\
\hline Country FE & $\checkmark$ & $\checkmark$ & $\checkmark$ & $\checkmark$ & $\checkmark$ & $\checkmark$ \\
\hline F-test joint GDP/c & 0.00 & 0.01 & 0.00 & 0.00 & 0.00 & 0.00 \\
\hline Mean dep. var. & 13.79 & 1.40 & 2.62 & 6.10 & 0.79 & 2.16 \\
\hline Countries & 125 & 125 & 125 & 125 & 125 & 125 \\
\hline Observations & 925 & 925 & 925 & 925 & 925 & 925 \\
\hline
\end{tabular}

Standard errors in parentheses, clustered at the country level. ${ }^{+} p<0.1,{ }^{*} p<0.05,{ }^{* *} p<0.01$. Employment data are taken from I2D2 and IPUMS (see Section 2), and data on GDP per capita in 2011 International Dollars are taken from the Penn World Table 9.0. The 'mean dependent variables' in columns (2)-(6) not exactly add up to the number for total manufacturing in column (1), as the total include some manufacturing workers in major group 5 ('service and sales workers') and 6 ('skilled agricultural, forestry and fishery workers'). However, these major groups tend to play a negligible role in manufacturing employment. 'F-test joint GDP/c' in the bottom panel presents the p-value of an F-test for joint significance of ln GDP per capita and its square. 
Table 2: Manufacturing employment as a function of income: period up to versus post-1990

Dependent variable: manufacturing employment in total employment, ages 15-64 (percentage points)

\begin{tabular}{|c|c|c|c|c|c|c|}
\hline & \multirow{3}{*}{$\frac{\text { Total }}{(1)}$} & \multicolumn{5}{|c|}{ Occupation split } \\
\hline & & (2) & (3) & (4) & (5) & (6) \\
\hline & & Elementary & Operators & Craftsmen & Clerks & Professionals \\
\hline \multirow[t]{2}{*}{$\ln \mathrm{GDP} / \mathrm{c}$} & 16.00 & -0.29 & 2.12 & 13.41 & 0.93 & -0.50 \\
\hline & $(13.22)$ & $(3.45)$ & $(6.17)$ & $(8.15)$ & $(1.86)$ & $(1.71)$ \\
\hline \multirow[t]{2}{*}{ ln GDP/c squared } & -0.81 & 0.06 & -0.04 & $-0.87^{+}$ & -0.03 & 0.08 \\
\hline & $(0.76)$ & $(0.20)$ & $(0.36)$ & $(0.46)$ & $(0.11)$ & $(0.10)$ \\
\hline \multirow[t]{2}{*}{ post-1990 } & $-81.00^{+}$ & -11.03 & $-40.22^{+}$ & -25.59 & $-11.01^{+}$ & 10.80 \\
\hline & $(45.74)$ & $(13.22)$ & $(23.00)$ & $(36.54)$ & $(6.01)$ & $(8.46)$ \\
\hline \multirow[t]{2}{*}{ ln GDP / c x post-1990 } & $21.54^{*}$ & 3.16 & $10.43^{+}$ & 6.03 & $3.02^{*}$ & -2.32 \\
\hline & $(10.64)$ & $(3.17)$ & $(5.62)$ & $(8.42)$ & $(1.43)$ & $(1.94)$ \\
\hline \multirow[t]{2}{*}{$\ln$ GDP /c squared x post-1990 } & $-1.39^{*}$ & -0.21 & $-0.66^{+}$ & -0.36 & $-0.20^{*}$ & 0.13 \\
\hline & $(0.61)$ & $(0.19)$ & $(0.34)$ & $(0.48)$ & $(0.08)$ & $(0.11)$ \\
\hline \multirow[t]{2}{*}{ ln population } & -2.42 & -0.17 & -0.01 & -2.21 & -0.28 & 0.27 \\
\hline & $(2.32)$ & $(0.49)$ & $(0.79)$ & $(2.32)$ & $(0.21)$ & $(0.40)$ \\
\hline \multirow[t]{2}{*}{ ln population squared } & 0.24 & 0.01 & -0.18 & $0.53^{*}$ & -0.04 & -0.08 \\
\hline & $(0.31)$ & $(0.09)$ & $(0.14)$ & $(0.26)$ & $(0.04)$ & $(0.06)$ \\
\hline Country fixed effects & $\checkmark$ & $\checkmark$ & $\checkmark$ & $\checkmark$ & $\checkmark$ & $\checkmark$ \\
\hline F-test joint GDP /c & 0.21 & 0.11 & 0.01 & 0.03 & 0.02 & 0.01 \\
\hline F-test joint GDP / c x post- 1990 & 0.00 & 0.02 & 0.06 & 0.71 & 0.00 & 0.43 \\
\hline Mean dep. var. & 13.79 & 1.40 & 2.62 & 6.10 & 0.79 & 2.16 \\
\hline Countries & 125 & 125 & 125 & 125 & 125 & 125 \\
\hline Observations & 925 & 925 & 925 & 925 & 925 & 925 \\
\hline
\end{tabular}

Standard errors in parentheses, clustered at the country level. ${ }^{+} p<0.1,{ }^{*} p<0.05,{ }^{* *} p<0.01$. The mean dependent variables in column (1) slightly exceeds the sum of columns (2)-(6) because it also includes manufacturing workers classified into major group 5 ('Service and sales workers') or major group 6 ('Skilled agricultural, forestry and fishery workers'). These occupations are omitted from the analyses by occupation group as they tend to represent a negligible share of manufacturing employment. The rows ' $F$-test joint GDP/c' in the bottom panel present the p-values of F-tests for joint significance of $\ln \mathrm{GDP} / \mathrm{c}$ and its square, with and without the post-1990 interaction. 


\section{Four Propositions about Premature Deindustrialization}

\section{Proposition I: It's mostly about Unskilled Jobs}

Table 3 presents average wage premia, educational attainments and average employment shares-both for non-manufacturing versus manufacturing, and by manufacturing occupation. Not all of the variables are available for surveys from all countries, and column (1) indicates the number of countries across which the sample average has been calculated. Columns (2) and (3) of the first panel show that on average, manufacturing workers tended to be relatively well paid: workers outside of manufacturing earned a $6.6 \log$ points lower wage than those within (for which the wage premium in the second row is zero by construction), and this holds true across all income groups ${ }^{13}$

My preferred proxy for the skill requirements of manufacturing occupations are wage premia, as they take into account both formal education and skills obtained through training on the job 14 Columns (4)(8) present average wage premia by occupation group, relative to the average manufacturing wage: the lowest-paid manufacturing workers were those in machine operator-, craftsman- and in particular elementary occupations, who earned wages $27 \log$ points below the manufacturing average in the pooled sample. Only in low income countries, machine operators commanded wages that were (insignificantly) above-average, and clerks were paid below the manufacturing average only in high income countries. The second and third panel show that also educational attainments of workers in elementary-, machine operator- or craftsman occupation tended to be below or similar to the manufacturing average.

Hence, premature deindustrialization is largely driven by relatively unskilled jobs in elementary and operator occupations. Medium-skilled clerks are also affected-but the bottom panel shows that they represent a much smaller share of manufacturing employment, in particular in low and middle income countries. It is worth noting that for most of the sample period, machine operators tended to be even less skilled than their relative wage in Table 3 suggests: about 80 percent of the underlying surveys with income data in this

\footnotetext{
${ }^{13}$ The corresponding p-values of tests for the equality of means are 0.00 for the pooled sample and high income countries, 0.10 for middle income countries, and 0.09 for low income countries. Since I am interested in comparisons between various pairs of workers, Table 3 omits tests for the significance of differences between means for the sake of readability. However, all differences discussed in the text are significant at p-values below 0.10 , unless indicated otherwise.

${ }^{14}$ As argued in Kunst et al. (2020), taking into account skills obtained through informal training is particularly important in developing countries-in which formal educational attainments are often low, and where large wage premia among workers with identical formal educational attainments are common.
} 
Table are from the year 2000 or later, so that the numbers are more representative for the later part of the sample period. Appendix Figure C.2 uses wages from the extended 'Occupational Wages around the World' database by Freeman and Oostendorp (2020) to show that in the 1950s, manufacturing operators earned wages that were on average $18 \log$ points below those of craftsmen- in contrast to Table 3 , which suggests somewhat higher wages for machine operators than for craftsmen 15

This also highlights a potential caveat of inferring changes in the demand for unskilled labor from changes in occupational employment: if machine operator jobs have become not only scarcer, but the remaining operator jobs also require higher skills, occupational employment trends understate the extent to which the demand for unskilled workers by manufacturing has decreased. One way of addressing this is to analyze the evolution of the wage premium that workers with a low educational attainment have been able to command in manufacturing, relative to other industries (irrespective of their occupation).

Figure 4 plots the evolution of this 'manufacturing wage premium' among all workers with less than completed primary schooling for the first and the last available year for the 12 countries with income data in IPUMS: a first observation is that in all surveys, unskilled workers earned substantially higher wages in manufacturing than in other industries. In the first year, they commanded 29 log points higher wages on average when working in manufacturing. However, the manufacturing wage premium decreased in 10 of the 12 countries, and the point estimate from a regression on country fixed effects and a trend suggests an average decrease by $3.7 \log$ points per decade.

Appendix Table C.2 shows that also in a sample of 88 countries-which includes all IPUMS and I2D2 surveys from countries with wage and educational attainment data for at least two years-, the point estimate implies a similar decrease in the manufacturing wage premium among workers with less than completed primary schooling of $3.3 \log$ points per decade. By contrast, there is no significant trend in the relative wage of workers with a higher education (which on average also did not earn higher wages in manufacturing as compared to other industries).

These findings are consistent with the results by Rodrik (2016): he shows that in a sample of 40 mostly high income countries in the 'World Input Output Database', it is the share of low-skilled workers who are

\footnotetext{
${ }^{15}$ However, the difference between average machine operator and craftsman wages in Table 3 is significant only for low income countries (pval=0.07). Kunst $(2019$ ) documents a pervasive decline in the relative wage of initially skilled craftsmen in manufacturing, and shows that this convergence of manufacturing wages in the 'blue collar'/ production occupations in countries of all income levels has been associated with increasing capital intensities of production.
} 
employed in manufacturing that has declined after 1995, whereas the shares of medium and high skilled workers have remained relatively constant 10 In summary, both occupational employment trends and the reduction of the 'manufacturing wage premium' among workers with little formal education suggest that premature deindustrialization reflects a reduction in manufacturing's ability to employ unskilled workers more productively than other industries.

\footnotetext{
${ }^{16}$ In the World Input Output Database, 'low-skilled' is defined as possessing at most lower secondary education. I choose a lower educational attainment-cut off to characterize workers with little formal education since my sample includes earlier years and more developing countries, so that educational attainments tend to be generally lower: among the samples with wage and education data (cf. column (1) of Appendix Table C.2 , on average 29 percent of the working-age population had less than completed primary schooling.
} 


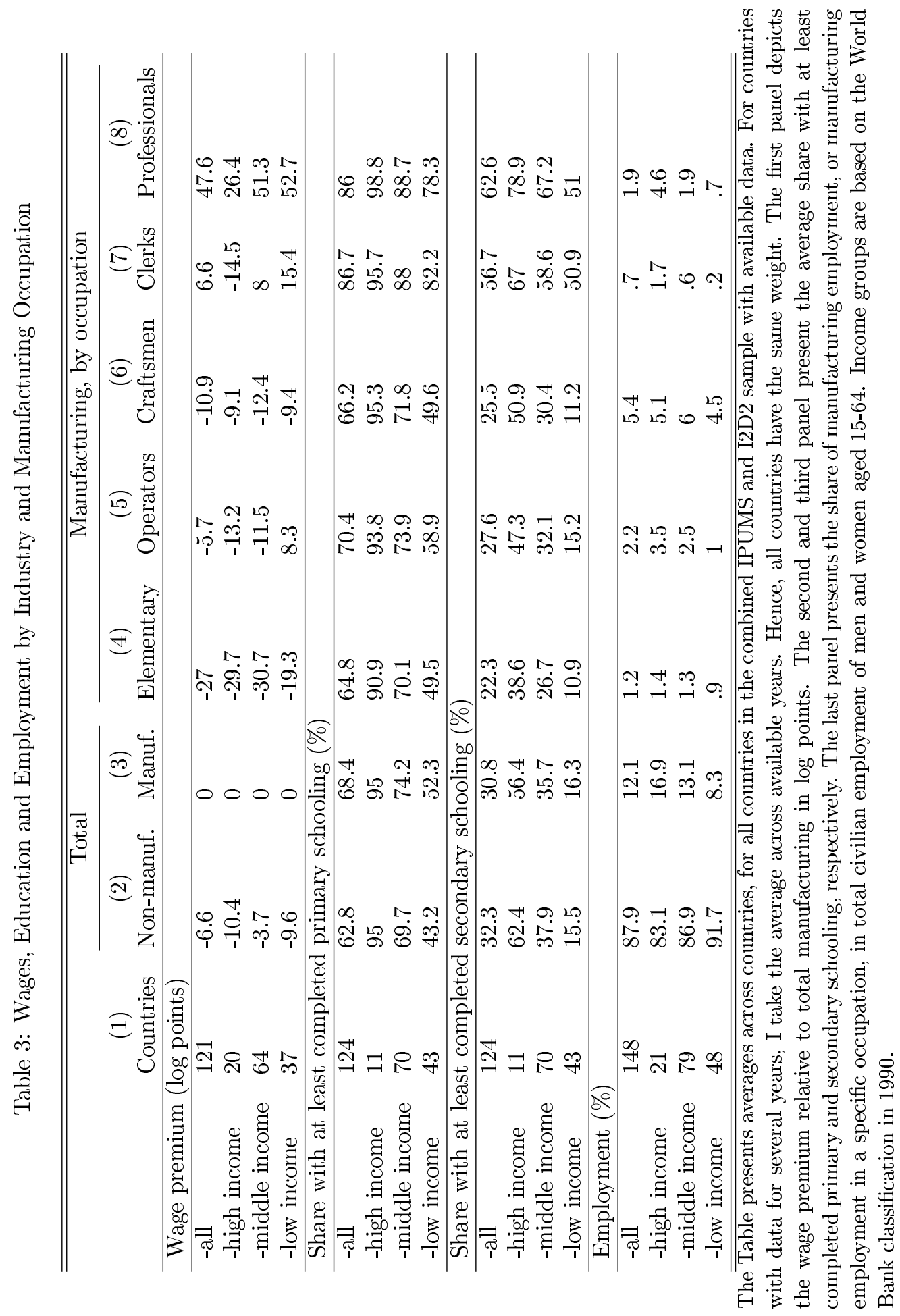




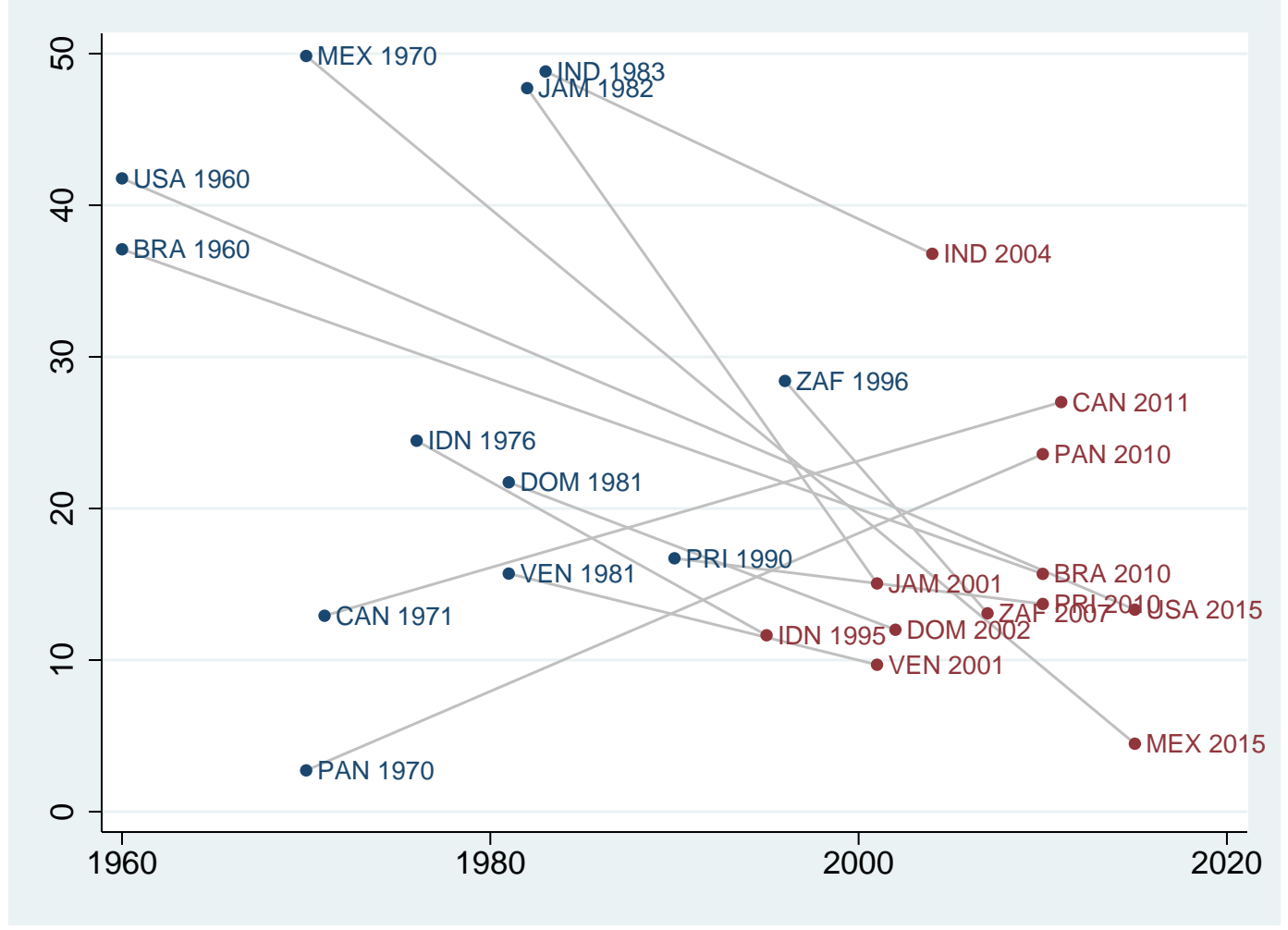

Figure 4: 'Manufacturing premium' among workers with less than completed primary schooling (in log points)

The Figure plots the first and the last year with income data in IPUMS. The manufacturing premium is calculated as $100^{*}$ the $\log$ ratio of income of those with at most incomplete primary schooling who are employed in manufacturing relative to those who work in a different industry. A regression on country fixed effects and a trend suggests an average decline of the the manufacturing premium by $3.7 \log$ points by decade, with a p-value of 0.075 when clustering standard errors at the country level. For samples with missing wage income, I use earned income as a proxy if available, and total income otherwise. For IPUMS surveys which include both wage and earned or total income, correlations between the manufacturing premia calculated using wage income with those based on earned or total income exceed 0.9 , suggesting that these are reasonable proxies.

\section{Proposition II: It's about Formal Jobs}

The benefits of increasing manufacturing employment are particularly large for formal manufacturing: Rodrik (2013a) shows that labor productivity in formal manufacturing exhibits 'unconditional convergence', closing the gap to the technology frontier at a rate of 2-3 percent per year. By contrast, La Porta and Shleifer (2008) paint a bleak picture of informal firms in developing countries: they are sharply less productive than 
formal ones, pay lower wages and usually stay informal, consistent with a 'dual economy' view of development ${ }^{17}$ Finally, Rodrik (2016) highlights the historical role of organized labor-associated with large, formal manufacturing establishments-in improving wages and employment conditions.

Table 4 summarizes various indicators of formality included in the surveys-again comparing total manufacturing with other industries, and distinguishing between the different manufacturing occupations. The most widely available formality indicator is the share of wage employment, presented in the first panel 18 Columns (2) and (3) show that in all income groups, manufacturing workers were more likely to be in wage employment than those in other industries. The bottom panel shows that manufacturing workers score higher also in terms of other measures of formality such as having an employment contract, and they tended to work in larger establishments that were more often located in urban areas 19

However, columns (4)-(8) show that there are large differences between manufacturing occupations: in particular workers in elementary-, machine operator- and clerical occupations were more likely to be wageemployed (84-93 percent on average in the pooled sample, versus only 57 percent for workers outside of manufacturing), whereas the 'formality gap' between manufacturing craftsmen and other industries is smaller and insignificant. Differences across manufacturing occupations are particularly striking for low and middle income countries: even compared to the manufacturing average, workers in elementary-, machine operatorand clerical occupations in these countries were between 13-42 percentage points more likely to be wage employed. Also the other formality indicators point in the same direction as craftsmen consistently score the lowest, pulling down the manufacturing average.

Appendix Table C.4 presents the results of regressions of the share of wage employment on country fixed effects and a trend: it suggests that the share of wage employment increased slightly over time for machine operators and professionals (by 1.6 and 1.0 percentage points per decade, respectively), but did not

\footnotetext{
${ }^{17}$ From this perspective, economic development comes from creating and growing formal manufacturing firms which displace informal manufacturing, rather than from a gradual process of business formalization. Also La Porta and Shleifer (2014) highlight this duality of manufacturing in developing countries, suggesting that some of the advantages of formal manufacturing may not carry over to informal manufacturing: 'although quality is difficult to measure, our visits to furniture and metal-working factories in Kenya and Madagascar revealed extreme crudeness of the products being made, usually with fairly basic tools, even when the raw material (as in the case of furniture) was hardwood. Informal factories appear to sell extremely low-quality goods for low prices to low-income customers.' (p. 113).

${ }^{18}$ Conversely, La Porta and Shleifer (2008) use the share of self-employment as a proxy for informality, and find a strong negative correlation with GDP per capita across countries.

${ }^{19}$ Differences between manufacturing and non-manufacturing averages are significant for the share of wage employment (pval $=0.00$, also for all income groups individually), as well as for 'contract', the firm size variables and 'urban' at p-values below 0.10 . Differences highlighted in the text below are also significant at p-values below 0.10 , unless indicated otherwise.
} 
change significantly for the other occupations. Hence, the cross-sectional ranking of occupations in terms of formality is likely to be representative for the sample period.

In summary, this suggests that premature deindustrialization is slowing down the formalization of labor markets: industrialization has traditionally created formal employment opportunities already at intermediate income levels mostly by creating elementary-, machine operator- and (to a lesser extent) clerical jobs. However, these are precisely the occupations accounting for the 'premature' employment losses.

\section{Proposition III: It's about Jobs that are Vulnerable to automation by ICT}

Manufacturing occupations differ not only in their skill-, but also in their task requirements. Hence, analyzing employment trends through the lens of occupations is informative about the origins of premature deindustrialization: to the extent that it is driven by technological change, one would expect an asymmetric reduction of employment in occupations that are intensive in tasks which have only recently become automatable also in developing countries. Has that been the case for machine operators, clerks and elementary occupations, but not for craftsmen and professionals?

The task descriptions in the definition of the ISCO major groups by the ILO, presented in Appendix B give a first indication of task differences between occupations. A second widely used measure is the Routine Task Intensity (RTI) index introduced by Autor and Dorn (2013): it summarizes the relative importance of routine- to non-routine tasks in an occupation, and has been used as a proxy for its vulnerability to automation by ICT 20

Figure 5 presents average RTI scores by occupation, standardized to have a mean of zero and a standard deviation of one for the overall labor market. All manufacturing occupations except for professionals score higher than zero, indicating an above-average vulnerability to automation by ICT. Clerks score particularly high-which is consistent with the ILO's assessment that their 'main tasks require the knowledge and experience necessary to organise, store, compute and retrieve information' (quoted from the description of major groups in Appendix B), and the notion that ICT has sharply reduced the need for workers to engage in such

\footnotetext{
${ }^{20}$ The task measures underlying the RTI index come from Autor et al. (2003), and are based on the 1977 edition of the US 'Dictionary of Occupational Titles'. I use the translation of these task scores into sub-major groups of ISCO by Goos et al. (2014). See Appendix Figure C.3 for the individual task scores by occupation, and an explanation for how they are aggregated into the RTI index.
} 


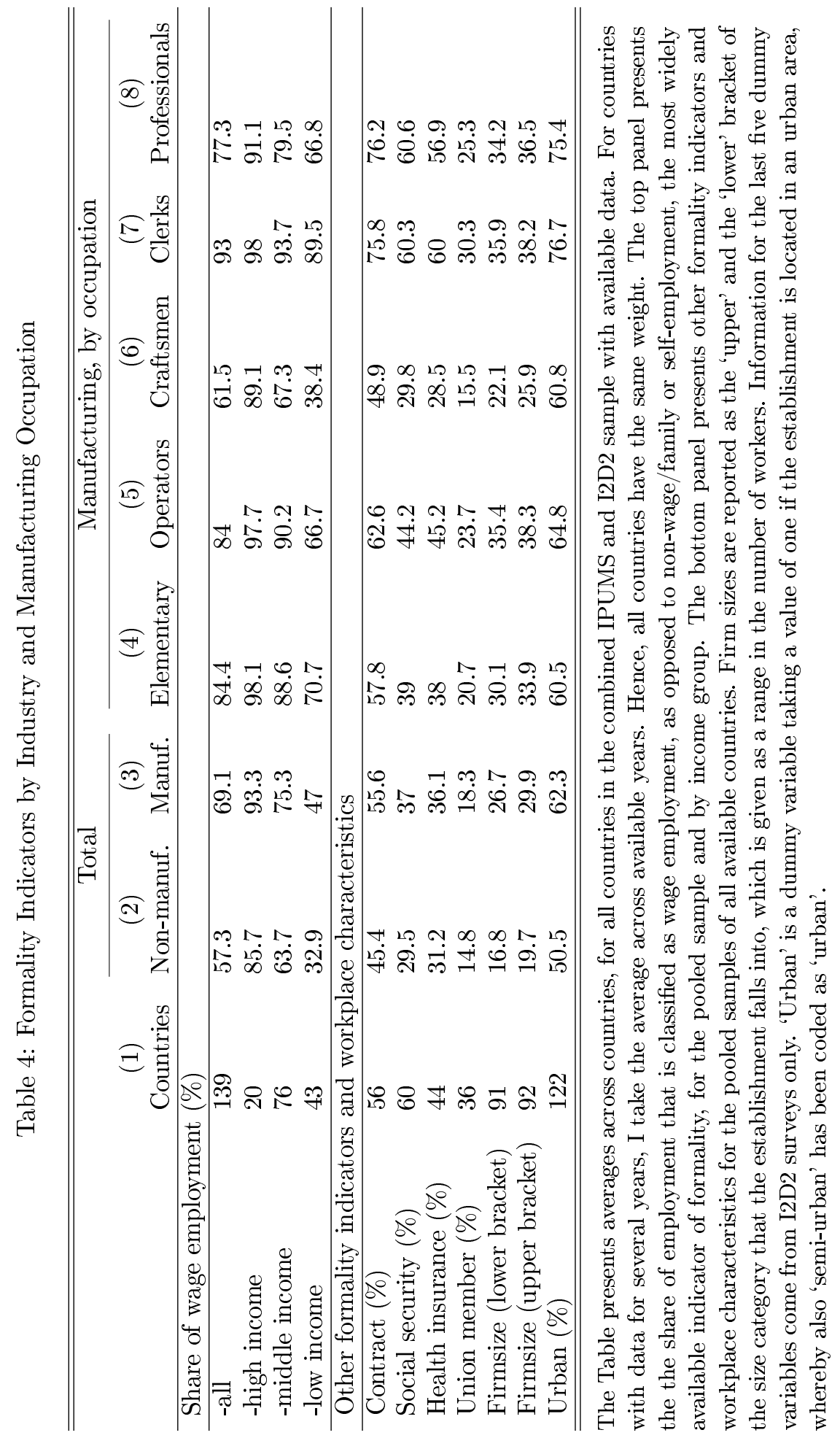


tasks.

Quantitatively more important are machine operators: their main tasks consist of 'operating and monitoring (...) production machinery and equipment'. While factory production with mechanically operated machines requires a large number of operators, it appears plausible that a move to more autonomous, digitally controlled machines reduces the need for unskilled human machine operators $\stackrel{21}{\square}$ Finally, elementary occupations require 'mostly simple and routine tasks'- and while the relation to ICT is somewhat less clear than for clerks and machine operators, it is well established that a move to more advanced continuous-process methods reduces the demand for unskilled laborers 22

At the other end of the routine task intensity spectrum, professionals engage in 'planning, directing and coordinating' and 'applying scientific and artistic concepts and theories to the solution of problems', which are tasks that are arguably more complementary to than substitutable for ICT. Next to professionals, also craftsmen have been spared from premature deindustrialization, although they score high on routine task intensity. One explanation is that manufacturing craftsmen have been vulnerable to automation even before the advent of ICT-as argued already by Jerome (1934) for the US, and documented for a wide range of countries since the 1950s by Kunst (2019) ${ }^{23}$ Hence, while craftsmen jobs continue to disappear with increasing automation already at low levels of income (as is apparent in Figure 3), there has not been a sharp reduction in the demand for craftsmen, conditional on income, after 199024

\footnotetext{
${ }^{21}$ Appendix Figure shows that machine operators have the second highest score on 'set limits, tolerances and standards'. Autor et al. (2003) use this task score as a measure for an occupation's demand for routine cognitive tasks, which appear particularly suitable to being taken over by digitally controlled machines.

${ }^{22}$ Continuous process methods take in raw materials and produce finished goods, with few hands intervening in production. Goldin and Katz (1998) argue that the adoption of such methods reduces the need for elementary occupations by automating hauling and conveying operations.

${ }^{23}$ According to ISCO, craftsmen are 'occupations whose tasks require the knowledge and experience of skilled trades or handicrafts'. For the US, Jerome (1934) predicts that 'the principal effect of further mechanization of the processing operations will be to decrease the demand for semiskilled workers. (...) On the whole, the shift will continue to be from the emphasis on the trade skill typical of the handicraftsman to, on the one hand, the alertness and intelligence required in handling fast and intricate machinery and, on the other, to the more formal training required in the engineering and production planning departments' (pp. 402-403).

${ }^{24}$ Because craftsmen score higher in terms of the RTI index than machine operators and elementary occupations, the association between the RTI index of an occupation group and its propensity to experience premature deindustrialization after 1990 is imperfect. Appendix Table C.5 tests whether it is still true that on average, occupation groups with a higher RTI score experienced significantly stronger premature deindustrialization: the sample corresponds to the one from Table 2 with the difference that it stacks the employment shares in the different occupations. To exploit the full available variation in RTI scores, it distinguishes between major groups 1-3 ('managers', 'professionals' and 'associate professionals'), which all have RTI scores below 0 and are subsumed into the 'professional' category in the rest of this paper. The specification includes country-occupation fixed effects, in analogy to the country fixed effects of the specifications in Table 2 The significant 'triple interactions' between the ln GDP per capita terms, the RTI index and the post-1990 dummy show that occupations with a high RTI index did on average experience stronger premature deindustrialization. Therefore, the argument that premature deindustrialization after 1990 has
} 
In summary, the evidence suggests that premature industrialization is characterized by job losses in occupations that appear particularly vulnerable to automation by ICT. As shown in Section 2, for these occupations it is only after 1990 that manufacturing employment starts to decline at intermediate income levels. This is consistent with evidence of increasing technology adoption in developing countries in recent decades: capital intensities in manufacturing have increased significantly in countries of all income levels (Kunst, 2019), and Jaumotte et al. (2013) show that also in developing countries, the share of ICT capital in the capital stock has increased rapidly after 1990. Also the World Bank's 2008 report on technology diffusion in developing countries concludes that the speed at which developing countries adopt new technologies has increased since 199025

been driven in particular by occupations that are vulnerable to ICT adoption is also robust to considering the RTI index as a perfect proxy for this vulnerability.

${ }^{25}$ The report concludes that 'since the early 1990s, technological progress in both low- and middle-income countries has increased more rapidly than in high-income countries' ( $\mathrm{p}$. xi), with the effect that 'the technology gap between middle-income and high-income countries has narrowed over the past 10 years' (p. 52). 


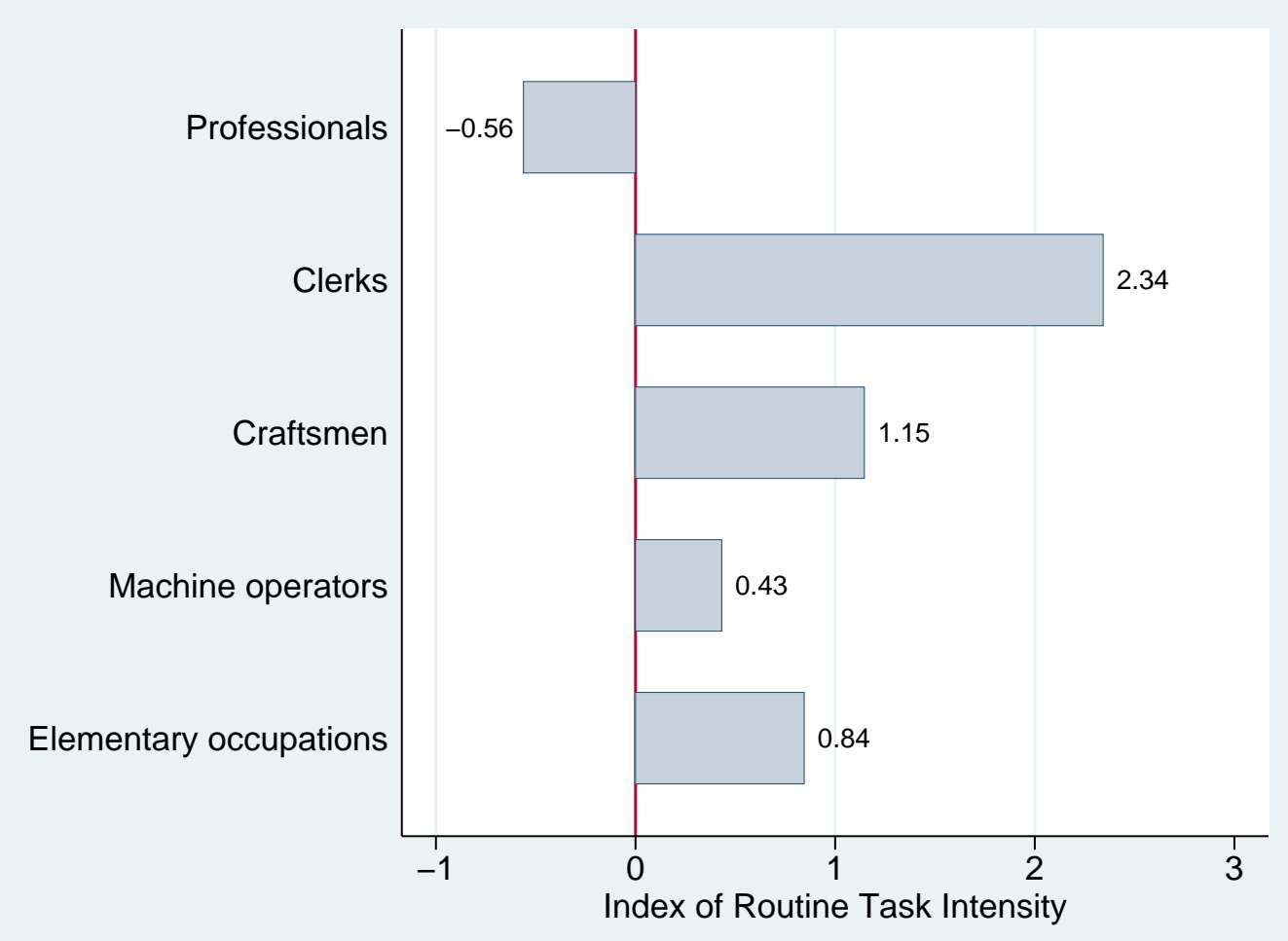

Figure 5: Routine task intensity scores by occupation

The routine task intensity (RTI) scores are calculated as in Autor and Dorn (2013), based on the translation of task scores from the 1977 US 'Dictionary of Occupational Titles' into sub-major groups of ISCO-88 by Goos et al. (2014). It is normalized to have a mean of zero and a standard deviation of one across these sub-major groups. The figure shows occupation group averages constructed from 11 sub-major groups that are relevant to manufacturing, as indicated by representation among the manufacturing occupations in the extended 'Occupational Wages Around the World' database (and hence, in the underlying ILO 'October Inquiry'- see Kunst et al. (2020) for more details). This excludes major groups 5 ('Service and sales workers') and 6 ('Skilled agricultural, forestry and fishery workers'), as well as some sub-major groups that do not play a role in manufacturing (for instance, sub-major group 23: 'Teaching Professionals').

\section{Proposition IV: Some Manufacturing Jobs also Appear at lower Levels of Income}

The simulations summarized in Figure 3 suggest that while manufacturing employment overall peaked at lower income and employment levels after 1990, low income countries actually saw more rather than less manufacturing employment ${ }^{26}$ One concern is that this finding may be driven by the implicitly assumed

\footnotetext{
${ }^{26}$ The curves intersect around $\$ 9,000$ for total manufacturing, $\$ 11,100$ for elementary occupations, $\$ 9,100$ for machine operators and $\$ 8,700$ for clerks-suggesting higher manufacturing employment below that income level after 1990 . In 2014 (the last
} 
symmetry when using a quadratic functional form. However, Figure 6 shows that for the joint employment share of machine operator, elementary and clerical occupations, also locally weighted regressions on the raw data suggest that low income countries have been spared from premature job losses, and possibly even had higher manufacturing employment after 1990 (conditional on income).27

The Goldin and Katz (1998) framework on the effects of technological change in manufacturing on labor demand offers an explanation: in their model, the 'first transition' from production in artisanal shops to factories increases the demand for unskilled workers in machine operator and elementary occupations, before further advances of the production technology reduce it.

While the original framework has been used to explain the US experience, it also appears relevant to recent labor demand trends in developing countries: Section 2 shows that manufacturing in low income countries still used to be dominated by craftsmen and hence relatively small-scale and artisanal. This is consistent with the characterization of manufacturing in developing countries in the literature review by Tybout (2000). Moreover, the evidence suggests that there has been an acceleration of technology adoption (as argued in the previous Section), which would be expected to change the composition of occupational labor demand towards occupations associated with larger-scale factory production 28

year in the sample), about 42 percent of the world population lived in countries with a GDP per capita below $\$ 9,000$ in 2011 international dollars- with China above, yet India below this income threshold. When translating the nominal World Bank income group-thresholds in 1990 to 2011 international dollars using the average Penn World Table price level estimates from the respective income group, the 'low income' country-threshold stood at about $\$ 2,100$, and the 'lower middle' income country threshold stood at about $\$ 9,900$. Hence, the simulations suggest that countries classified as low income countries in 1990 , as well as many lower middle income countries, have been spared from premature deindustrialization.

${ }^{27}$ For clerical occupations, the finding of 'early industrialization' in low income countries depends on the quadratic functional form and country fixed effects. However, also the evidence from locally weighted regressions suggests that low income countries have at least been spared from premature deindustrialization with respect to clerical as well as total manufacturing employment. See Appendix Figure C.4 for plots of the raw data separately for total manufacturing and each occupation, which also include the fitted lines from a locally weighted regression for both periods.

${ }^{28}$ The World Bank report on technology adoption (World Bank 2008) highlights that technological change in developing countries has mostly taken the form of adopting technologies that had already been well established in high income countries, as opposed to innovations from developing countries themselves: 'while a strong correlation exists between scientific innovation and invention and income in high-income countries, almost none of this kind of activity is being performed in developing countries. As a result, virtually all technological progress in developing countries comes from the adoption and adaptation of preexisting technologies' (p. 52). Often, these are the same machines that had previously been used in high income countries, and which are imported as 'vintage capital' (Navaretti et al., 2000). 


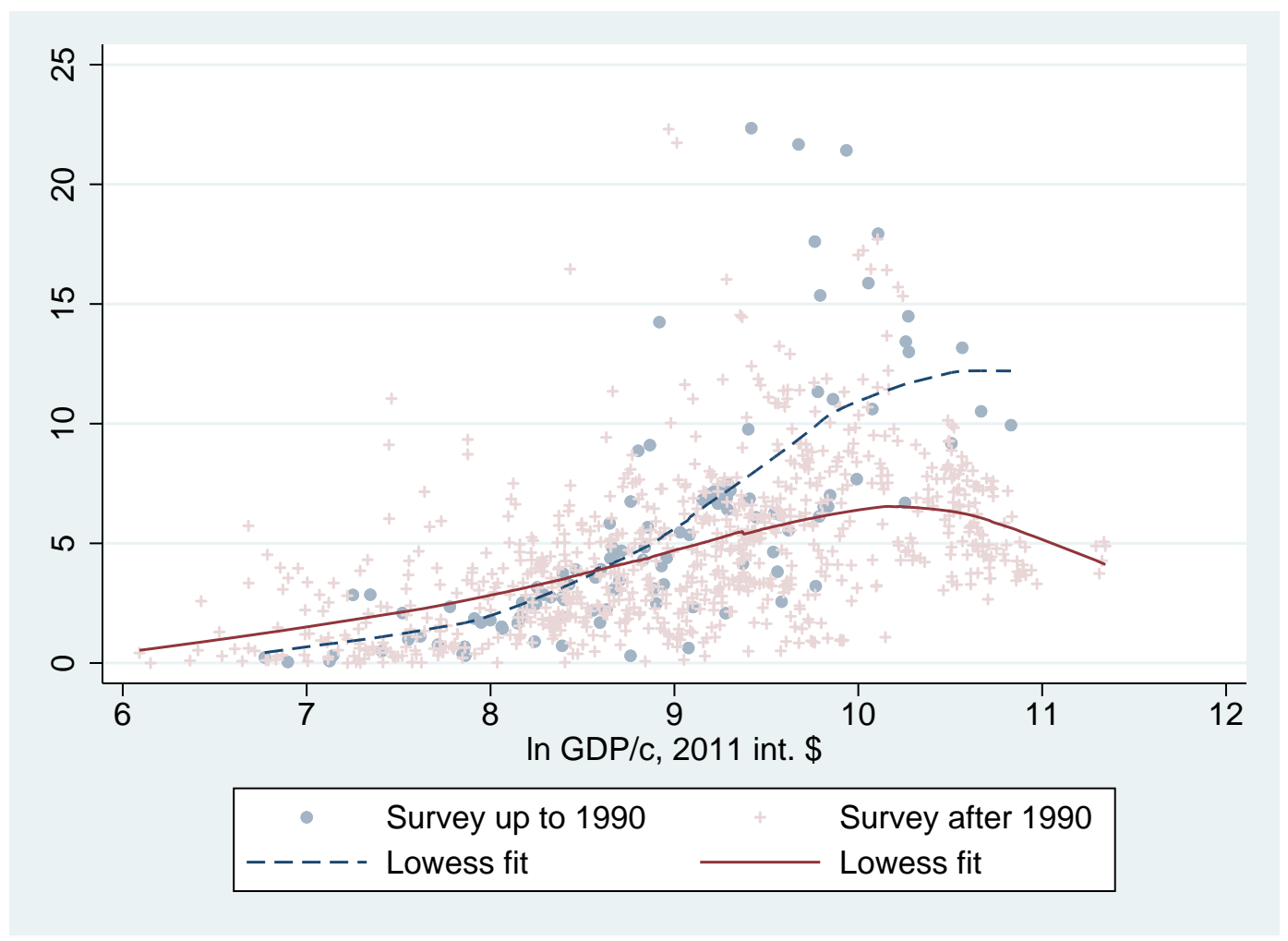

Figure 6: Manufacturing employment in joint machine operator, elementary and clerical occupations Every dot represents the joint manufacturing employment share in machine operator, elementary or clerical occupations from a country-year up to or after 1990. Moreover, the Figures include non-parametric estimates of the employment shares by GDP per capita in both periods, produced using the 'lowess' command in Stata, using the default bandwidth.

For concrete examples of changes in the joint employment share of machine operator, elementary and clerical occupations after 1990, Figure 7 plots the employment share from the first and the last year for the 121 countries with at least two surveys from that period. The Figure connects and labels observations from the 10 countries which experienced the largest decrease in machine operator, elementary and clerical employment, and the 10 countries experiencing the largest increase. 6 of the 10 countries with the largest decreases were classified as middle income countries in 1990 (such as South Africa/ZAF, Costa Rica/CRI and Jamaica/JAM), whereas 7 of the 10 countries with the largest increases were classified as low income countries (such as Cambodia-/KHM, Ethiopia/ETH and Liberia/LBR) 29

\footnotetext{
${ }^{29}$ China, another low income country in 1990 , is just outside of the top 10 of countries with the largest increases, with an increase in the joint machine operator, elementary and clerical employment share by 3.1 percentage points between 2002 and
} 
Diao et al. (2017b) argue that in Ethiopia, employment gains in light manufacturing since the early 1990s have been based on the processing of agricultural products, and are the result of successful efforts of the Ethiopian government to attract foreign investors. McMillan et al. (2014) and Diao et al. (2017a) point to recent manufacturing employment gains in several additional African low-income countries, also suggesting that such gains have not been limited to Asia 30 Finally, Appendix Table C.3 shows that also the decrease of the manufacturing wage premium among unskilled workers has been driven by middle income countries, whereas the point estimate is smaller and insignificant (though still negative) for low income countries.

2013. Moroever, note that the data for Bangladesh ('BGD'), a low income country for which the Figure suggests strongly decreasing manufacturing employment in joint machine operator, elementary and clerical employment, appears dubious: the surveys suggest increasing total manufacturing employment between both years (2000 and 2013), driven by strongly increasing craftsman employment. Moreover, there is no evidence of such a shift from elementary, operator or clerical to craftsman occupations in the previous available survey from 2010.

${ }^{30}$ Diao et al. (2017a) conclude that 'although the employment share in manufacturing is not expanding rapidly, in most of the low-income African countries the employment share in manufacturing has not peaked and is still expanding, albeit from very low levels' (p. 28). 


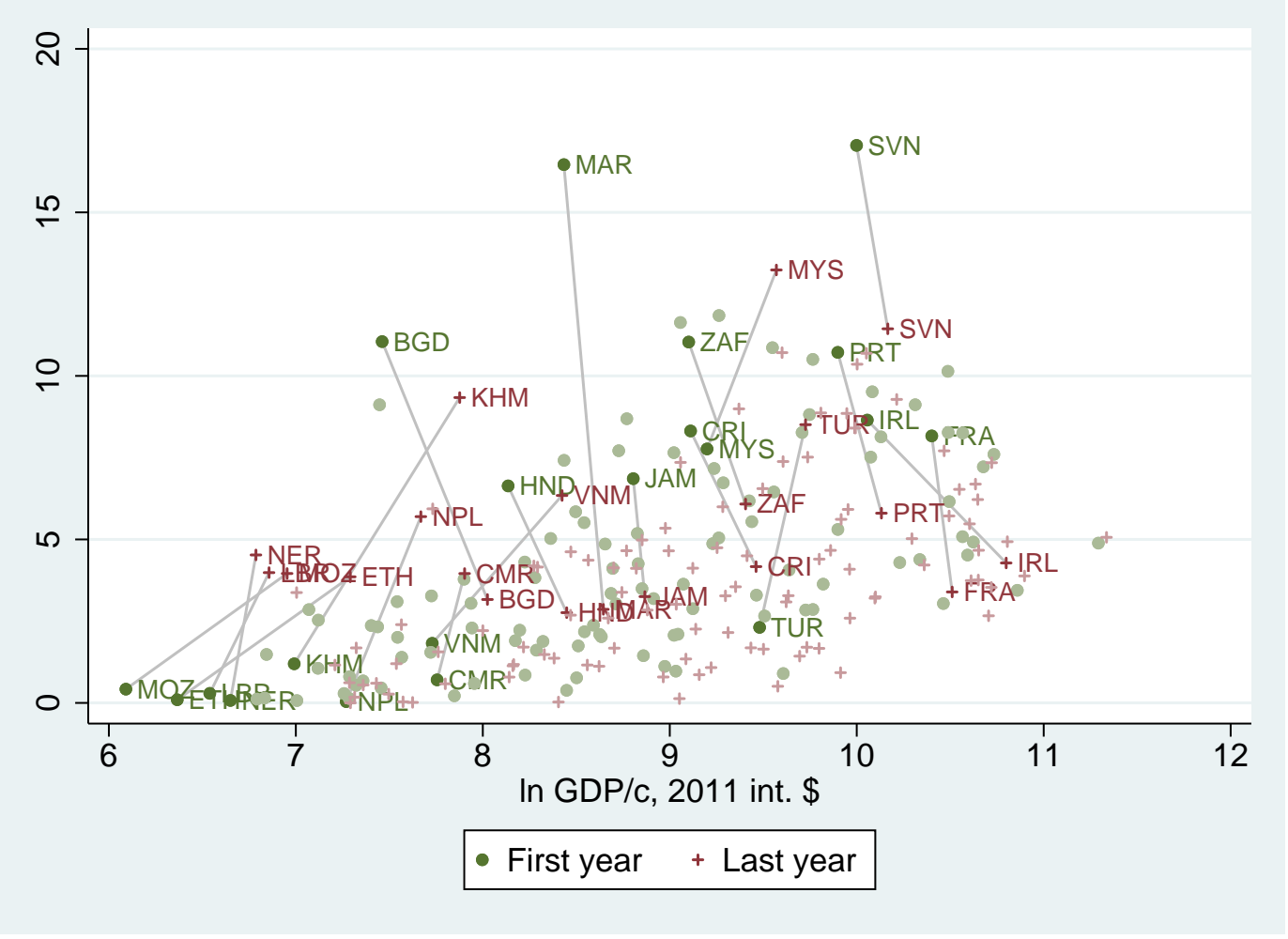

Figure 7: Employment changes after 1990 in joint machine operator, elementary and clerical employment For 121 countries with at least two surveys after 1990, the Figure plots the joint manufacturing employment share in machine operator, elementary and clerical occupations for both the first and the last year in the sample (on average, these years are 1998 and 2010). For the 10 countries with the largest employment gains or losses in these occupations, I connect both observations and assign a country label. The employment share in the bottom 10 countries on average decreased by 5.8 percentage points, and 6 of them were classified as middle income countries in 1990. The top 10 countries on average increased their employment share by 4.9 percentage points between both years, and 7 of them were classified as low income countries in 1990.

In summary, the evidence suggests that premature deindustrialization has to date spared low income countries. There are even some signs of increasing manufacturing employment conditional on income for poorer developing countries in elementary, machine operator and clerical occupations. This is consistent with the view that the move from artisanal to more modern, larger-scale production creates opportunities for employment industrialization in low income countries-in particular if they follow the example of countries like Cambodia or China by tapping into foreign demand for consumer goods in relatively low-tech manufacturing industries such as garments, footwear or electronics assembly. 


\section{Concluding Remarks}

Occupational employment trends paint a nuanced picture of the future prospects for manufacturing-led growth in developing countries: on the one hand, the trend towards more open goods and capital markets appears to facilitate some employment industrialization in low income countries by increasing technology transfer and export opportunities 11 At the same time, this technology transfer appears to have markedly reduced employment opportunities in unskilled, yet formal, machine operator, elementary and clerical occupations even in middle income countries in recent decades, resulting in much lower peak manufacturing employment shares in these occupations.

It is useful to compare this account with Akamatsu's (1962) 'flying geese paradigm' of development: in his metaphor, the technologically most advanced countries are 'chased' by exporters of consumer goods, which are in turn chased by exporters of raw materials, the least advanced countries. The occupational employment pattern can then be understood as resulting from a reduction in the technological distance between countries (or as 'geese flying closer together'): low income countries move towards the export of consumer goods such as garments, creating employment in the more formal manufacturing occupations, whereas middle income countries adopt the capital- and skill-intensive production technologies of the most advanced countries, resulting in employment losses in the occupations that are most vulnerable to ICT adoption ${ }^{32}$

The notion of a convergence of manufacturing production technologies is consistent with China, a middle income country, being the largest buyer of high-tech industrial robots in 2017, accounting for more than a third of global robot sales (International Federation of Robotics, 2018). It is also consistent with the findings of Kunst (2019), which documents that capital intensities in manufacturing have increased substantially over recent decades also in developing countries-with profound impacts on the structure of occupational employment and wages. Finally, it is in line with both stylized facts emerging from the historical account

\footnotetext{
${ }^{31}$ See Jaumotte et al. (2013) for an illustration of the increases in various measures of trade and financial openness by income group since 1980 .

${ }^{32}$ In the notation of Akamatsu (1962), low income countries are moving from stages one and two (import of consumer goods and production for the domestic market) to stage three (export of consumer goods), whereas middle income countries join high income countries by moving from stage three to stage four (product differentiation and export of capital goods). Akamatsu also acknowledges that the distance between the 'flying geese' can vary over time: 'however, these countries, advanced and less advanced, do not necessarily go forward at the same speed in their development of a wild-geese-flying pattern, nor do they always make gradual progress, but they are at times dormant and at other times make leaping advances' (p. 18).
} 
of technology adoption by Comin and Hobijn (2010): while there are large cross-country differences in the extent to which new technologies are adopted, the adoption lag length has decreased over time.

From this perspective, premature deindustrialization is the result of a global shift of the frontier separating manufacturing tasks that are automated from those that are still performed by human labor. Therefore, it appears unlikely that China further moving up the development ladder will bring back unskilled manufacturing employment on a large scale to other developing countries, as suggested by Haraguchi et al. (2017). Rather, the question is whether further shifts of the 'automation frontier' will reduce the scope for even the moderate increases in unskilled manufacturing employment that still prevails today in low income countries.

Note that this account does not negate the role of globalization in creating premature deindustrialization: first, because increasing openness has facilitated technology transfer-and has also increased the pressure to adopt more advanced production technologies via stronger import competition, as well as increased the benefits of doing so by facilitating the access to the markets of high income countries (featuring higher quality standards). Second, because the emergence of global value chains with consecutive and interdependent production steps has reduced the scope of manufacturing firms in developing countries to substitute capital with unskilled labor, as argued by Rodrik (2018). This is consistent with the decrease in the 'manufacturing premium' of unskilled workers documented in this paper ${ }^{33}$ And finally, because the manufacturing employment gains in some low income countries (proposition IV) leave open the possibility that increasing labor cost competition from these countries has also contributed to the premature deindustrialization-phenomenon.

250 years after the beginning of the Industrial Revolution, it appears that manufacturing is losing its ability to employ unskilled workers more productively than other industries. As Rodrik (2018) points out, this implies that developing countries, abundant in unskilled labor, lose their comparative advantage in producing an increasing range of manufactured goods 34 Hence, future growth in developing countries may have to rely more on improvements in 'fundamentals' such as education and governance, and policy makers

\footnotetext{
${ }^{33}$ Global value chains may also have affected manufacturing occupations asymmetrically, as they entail the relocation of specific production tasks-as opposed to entire production processes-across countries. However, Reijnders and de Vries (2018) decompose the changes in routine versus non-routine jobs in thirty-seven advanced and emerging countries over the period 1999-2007 into those that are due to technological change and those that are due to task relocation, and find that the contribution of technological change has been an order of magnitude larger (cf. their Figure F.2). This suggests that technological change within countries has been the main proximate driver of the asymmetric deindustrialization trends across manufacturing occupations documented in this paper.

${ }^{34}$ This is also evidenced by the increasing attention to the phenomenon of 'reshoring' of production to high income countries (Gray et al. 2013).
} 
need to focus on a broader range of sectoral policies than in the past (Stiglitz, 2018). Absent a reduction in the 'formality gap' between manufacturing and other industries, it will also create employment that is less formal.

\section{Acknowledgements}

I am grateful to Peter F. Lanjouw and Remco Oostendorp for their detailed suggestions which have greatly improved the paper, and to Dani Rodrik, Gaaitzen de Vries and seminar participants at the Vrije Universiteit Amsterdam for helpful comments. I am also grateful to Anna Salomons for sharing her occupational task scores with me, and to Kathleen G. Beegle, Claudio E. Montenegro, David Newhouse and Aditi Mishra for their help in accessing the surveys from the World Bank International Income Distribution database. This research did not receive any specific grant from funding agencies in the public, commercial, or not-for-profit sectors.

\section{References}

Akamatsu, K. (1962). A historical pattern of economic growth in developing countries. The Developing Economies, 1:3-25.

Amirapu, A. and Subramanian, A. (2015). Manufacturing or services? an Indian illustration of a development dilemma. Technical report, Center for Global Development Working Paper 408.

Autor, D., Levy, F., and Murnane, R. J. (2003). The skill content of recent technological change: An empirical exploration. Quarterly Journal of Economics, 118(4):1279-1333.

Autor, D. H. and Dorn, D. (2013). The growth of low-skill service jobs and the polarization of the US labor market. American Economic Review, 103(5):1553-1597.

Comin, D. and Hobijn, B. (2010). An exploration of technology diffusion. American Economic Review, 100(5):2031-59. 
Dasgupta, S. and Singh, A. (2006). Manufacturing, services and premature deindustrialization in developing countries: A Kaldorian analysis. Technical report, WIDER Research Paper No. 2006/49.

Diao, X., Harttgen, K., and McMillan, M. (2017a). The changing structure of Africa's economies. World Bank Economic Review, 31(2):412-433.

Diao, X., McMillan, M., and Wangwe, S. (2017b). Agricultural labour productivity and industrialisation: lessons for Africa. Journal of African Economies, 27(1):28-65.

Feenstra, R. C., Inklaar, R., and Timmer, M. P. (2015). The next generation of the Penn World Table. American Economic Review, 105(10):3150-3182.

Felipe, J., Mehta, A., and Rhee, C. (2018). Manufacturing matters... but it's the jobs that count. Cambridge Journal of Economics, 43(1):139-168.

Freeman, R. B. and Oostendorp, R. (2020). The Occupational Wages around the World 1953-2008 Database. https://data.nber.org/oww/.

Goldin, C. and Katz, L. F. (1998). The origins of technology-skill complementarity. Quarterly Journal of Economics, 113(3):693-732.

Goos, M., Manning, A., and Salomons, A. (2014). Explaining job polarization: Routine-biased technological change and offshoring. American Economic Review, 104(8):2509-2526.

Gray, J. V., Skowronski, K., Esenduran, G., and Rungtusanatham, M. J. (2013). The reshoring phenomenon: what supply chain academics ought to know and should do. Journal of Supply Chain Management, $49(2): 27-33$.

Haraguchi, N., Cheng, C. F. C., and Smeets, E. (2017). The importance of manufacturing in economic development: Has this changed? World Development, 93:293-315.

International Federation of Robotics (2018). World robotics 2018 industrial robots. Technical report, International Federation of Robotics (IFR) Statistical Department. 
Jaumotte, F., Lall, S., and Papageorgiou, C. (2013). Rising income inequality: technology, or trade and financial globalization? IMF Economic Review, 61(2):271-309.

Jerome, H. (1934). Mechanization in industry, no. 27. National Bureau of Economic Research, New York.

Kunst, D. (2019). Deskilling among manufacturing production workers. Technical report, Tinbergen Institute Discussion Paper 19-050/VI.

Kunst, D., Freeman, R. B., and Oostendorp, R. (2020). Occupational skill premia around the world. Technical report, NBER Working Paper 26863.

La Porta, R. and Shleifer, A. (2008). The unofficial economy and economic development. Brookings Papers on Economic Activity, 2008:275-352.

La Porta, R. and Shleifer, A. (2014). Informality and development. Journal of Economic Perspectives, 28(3):109-26.

Lewis, W. A. (1954). Economic development with unlimited supplies of labour. The Manchester School, 22(2):139-191.

McMillan, M., Rodrik, D., and Verduzco-Gallo, I. (2014). Globalization, structural change, and productivity growth, with an update on Africa. World Development, 63:11-32.

Minnesota Population Center (2018). Integrated public use microdata series, international: Version 7.1. https://doi.org/10.18128/D020.V7.1.

Montenegro, C. E. and Hirn, M. L. (2009). A new disaggregated set of labor market indicators using standardized household surveys from around the world. Technical report, World Bank, World Development Report Background Paper.

Navaretti, G. B., Soloaga, I., and Takacs, W. (2000). Vintage technologies and skill constraints: Evidence from us exports of new and used machines. World Bank Economic Review, 14(1):91-109.

Reijnders, L. S. and de Vries, G. J. (2018). Technology, offshoring and the rise of non-routine jobs. Journal of Development Economics, 135:412-432. 
Rodrik, D. (2013a). Structural change, fundamentals, and growth: an overview. Technical report, Institute for Advanced Study.

Rodrik, D. (2013b). Unconditional convergence in manufacturing. Quarterly Journal of Economics, 128(1):165-204.

Rodrik, D. (2016). Premature deindustrialization. Journal of Economic Growth, 21(1):1-33.

Rodrik, D. (2018). New technologies, global value chains, and developing economies. Technical report, NBER Working Paper 25164.

Rowthorn, R. and Coutts, K. (2004). De-industrialisation and the balance of payments in advanced economies. Cambridge Journal of Economics, 28(5):767-790.

Stiglitz, J. E. (2018). From manufacturing-led export growth to a twenty-first-century inclusive growth strategy. Technical report, WIDER Working Paper 2018/176.

Timmer, M., de Vries, G. J., and de Vries, K. (2015a). Patterns of structural change in developing countries. In Routledge Handbook of Industry and Development, pages 79-97. Routledge.

Timmer, M. P., Dietzenbacher, E., Los, B., Stehrer, R., and Vries, G. J. (2015b). An illustrated user guide to the world input-output database: the case of global automotive production. Review of International Economics, 23(3):575-605.

Tybout, J. R. (2000). Manufacturing firms in developing countries: How well do they do, and why? Journal of Economic Literature, 38(1):11-44.

World Bank (2008). Technology diffusion in the developing world. Technical report, World Bank. World Bank Global Economic Prospects.

\section{A Sample Construction and Coverage}

The first data source is the 'International Income Distribution data set' (I2D2), which is a harmonized collection of nationally representative and harmonized household surveys maintained by the World Bank. It 
is first described in Montenegro and Hirn (2009), but has been extended significantly since then. The data in this paper are based on the full I2D2 database as of March 2019. I2D2 draws on a variety of surveys such as labor force surveys, budget surveys, and the World Bank's Living Standards Measurement Surveys. Industry and occupation codes are harmonized to the 1-digit level of ISIC and ISCO, respectively. I calculate employment shares for all men and women aged 15-64 in civilian employment, using the survey weights. If several surveys are available for a country-year, I take the average values across surveys, using the square root of the number of manufacturing observations as weight. I2D2 includes surveys from 139 countries, but has very limited coverage for years before 1990 .

I hence complement I2D2 with the surveys of the Integrated Public Use Microdata Series (IPUMS), provided by the Minnesota Population Center (2018). IPUMS contains data with 1-digit level of ISIC and ISCO codes from 76 countries, the large majority of which are census extracts. I again calculate employment shares for all men and women aged 15-64 in civilian employment, using the person weights. Finally, I combine the I2D2 and IPUMS surveys. If a country-year observation is available from both sources, I give preference to the IPUMS data, as IPUMS census extracts tend to contain a larger number of observations and the sampling is likely to be more harmonized 35 I did not engage in any further 'cleaning' of the resulting data set.

The combined sample includes manufacturing employment shares from 148 countries and 980 countryyears between 1960 and 2016. The main sample used in the regression analyses excludes countries for which the Penn World Table 9.0 (Feenstra et al. 2015) does not include data on real GDP per capita, or for which data are available for only a single year. This sample includes data for 925 country-years between 1960 and 2014. 112 of the country-years are from the period up to 1990. For 43 countries, at least one survey from both up to and after 1990 is available. The Tables below summarize the data availability by country in the main sample.

The additional 23 countries, which enter into the calculations in Table 3 are: Afghanistan, Bahamas, Barbados, Belarus, Burundi, Chad, Croatia, Côte d'Ivoire, Djibouti, Guyana, Kiribati, Kosovo, Marshall Islands, Micronesia, Papua New Guinea, Puerto Rico, Solomon Islands, South Sudan, Sudan, St. Lucia, Timor-Leste, Togo, Tonga.

\footnotetext{
${ }^{35}$ For 47 country-years from 30 countries, I have estimates from both I2D2 and IPUMS. The correlation between the estimated employment shares for total manufacturing from both sources is 0.88 .
} 
Table A.1: 43 countries with samples in both periods (up to and post-1990)

\begin{tabular}{|c|c|c|c|c|c|}
\hline & First year & Last year & Total surveys & -to 1990 & -post 1990 \\
\hline ARG - Argentina & 1970 & 2014 & 12 & 2 & 10 \\
\hline AUT - Austria & 1971 & 2008 & 9 & 2 & 7 \\
\hline BEN - Benin & 1979 & 2013 & 4 & 1 & 3 \\
\hline BOL - Bolivia & 1976 & 2014 & 16 & 1 & 15 \\
\hline BRA - Brazil & 1960 & 2014 & 27 & 13 & 14 \\
\hline CAN - Canada & 1971 & 2011 & 5 & 2 & 3 \\
\hline CHE - Switzerland & 1970 & 2000 & 4 & 3 & 1 \\
\hline CHL - Chile & 1960 & 2013 & 16 & 5 & 11 \\
\hline CRI - Costa Rica & 1973 & 2012 & 15 & 2 & 13 \\
\hline DEU - Germany & 1970 & 2008 & 6 & 2 & 4 \\
\hline DOM - Dominican Republic & 1960 & 2013 & 10 & 3 & 7 \\
\hline ECU - Ecuador & 1962 & 2014 & 12 & 3 & 9 \\
\hline EGY - Egypt, Arab Rep. & 1986 & 2006 & 7 & 2 & 5 \\
\hline ESP - Spain & 1981 & 2011 & 11 & 1 & 10 \\
\hline FJI - Fiji & 1976 & 2008 & 4 & 1 & 3 \\
\hline FRA - France & 1962 & 2011 & 12 & 5 & 7 \\
\hline GHA - Ghana & 1984 & 2012 & 7 & 1 & 6 \\
\hline GIN - Guinea & 1983 & 1994 & 2 & 1 & 1 \\
\hline GRC - Greece & 1971 & 2011 & 10 & 2 & 8 \\
\hline HND - Honduras & 1961 & 2014 & 22 & 2 & 20 \\
\hline HTI - Haiti & 1982 & 2007 & 3 & 1 & 2 \\
\hline IDN - Indonesia & 1971 & 2009 & 19 & 5 & 14 \\
\hline IND - India & 1983 & 2011 & 8 & 2 & 6 \\
\hline IRL - Ireland & 1971 & 2011 & 13 & 3 & 10 \\
\hline JAM - Jamaica & 1982 & 2002 & 7 & 2 & 5 \\
\hline
\end{tabular}




\begin{tabular}{|c|c|c|c|c|c|}
\hline MAR - Morocco & 1982 & 2004 & 5 & 1 & 4 \\
\hline MEX - Mexico & 1970 & 2010 & 15 & 3 & 12 \\
\hline MLI - Mali & 1987 & 2009 & 4 & 1 & 3 \\
\hline MWI - Malawi & 1987 & 2013 & 5 & 1 & 4 \\
\hline MYS - Malaysia & 1970 & 2000 & 4 & 2 & 2 \\
\hline NIC - Nicaragua & 1971 & 2009 & 7 & 1 & 6 \\
\hline PAK - Pakistan & 1973 & 2014 & 15 & 1 & 14 \\
\hline PAN - Panama & 1960 & 2012 & 22 & 5 & 17 \\
\hline PRT - Portugal & 1981 & 2011 & 9 & 1 & 8 \\
\hline PRY - Paraguay & 1962 & 2012 & 9 & 3 & 6 \\
\hline SEN - Senegal & 1988 & 2001 & 3 & 1 & 2 \\
\hline THA - Thailand & 1981 & 2011 & 18 & 9 & 9 \\
\hline TTO - Trinidad and Tobago & 1980 & 2000 & 3 & 2 & 1 \\
\hline TUR - Turkey & 1985 & 2010 & 13 & 2 & 11 \\
\hline URY - Uruguay & 1963 & 2014 & 21 & 2 & 19 \\
\hline USA - United States & 1960 & 2010 & 7 & 4 & 3 \\
\hline VEN - Venezuela, RB & 1981 & 2006 & 9 & 3 & 6 \\
\hline ZMB - Zambia & 1990 & 2014 & 9 & 1 & 8 \\
\hline TOTAL & 1960 & 2014 & 439 & 110 & 329 \\
\hline
\end{tabular}

Table A.2: 82 countries with samples in one period (up to or post-1990)

\begin{tabular}{llllll}
\hline \hline & First year & Last year & Total surveys & -to 1990 & -post 1990 \\
\hline AGO - Angola & 2000 & 2014 & 3 & 0 & 3 \\
ALB - Albania & 2002 & 2008 & 3 & 0 & 3 \\
ARM - Armenia & 2011 & 2013 & 2 & 0 & 2 \\
AUS - Australia & 2001 & 2010 & 10 & 0 & 10
\end{tabular}




\begin{tabular}{|c|c|c|c|c|}
\hline BEL - Belgium & 2004 & 2011 & 8 & 0 \\
\hline BFA - Burkina Faso & 1996 & 2014 & 4 & 0 \\
\hline BGD - Bangladesh & 2000 & 2013 & 5 & 0 \\
\hline BGR - Bulgaria & 2003 & 2010 & 5 & 0 \\
\hline BIH - Bosnia and Herzegovina & 2001 & 2007 & 2 & 0 \\
\hline BLZ - Belize & 1993 & 1999 & 6 & 0 \\
\hline BTN - Bhutan & 2003 & 2012 & 3 & 0 \\
\hline BWA - Botswana & 1991 & 2011 & 5 & 0 \\
\hline CHN - China & 2002 & 2013 & 4 & 0 \\
\hline CMR - Cameroon & 2001 & 2014 & 5 & 0 \\
\hline COL - Colombia & 1964 & 1973 & 2 & 2 \\
\hline COM - Comoros & 2004 & 2013 & 2 & 0 \\
\hline CPV - Cabo Verde & 2000 & 2007 & 2 & 0 \\
\hline CYP - Cyprus & 2005 & 2008 & 4 & 0 \\
\hline CZE - Czech Republic & 2005 & 2008 & 4 & 0 \\
\hline DNK - Denmark & 2004 & 2008 & 5 & 0 \\
\hline EST - Estonia & 2000 & 2008 & 9 & 0 \\
\hline ETH - Ethiopia & 1995 & 2014 & 12 & 0 \\
\hline FIN - Finland & 2004 & 2008 & 5 & 0 \\
\hline GBR - United Kingdom & 1991 & 2008 & 6 & 0 \\
\hline GEO - Georgia & 2008 & 2013 & 6 & 0 \\
\hline GMB - Gambia, The & 1998 & 2010 & 3 & 0 \\
\hline GTM - Guatemala & 2000 & 2006 & 5 & 0 \\
\hline HUN - Hungary & 2001 & 2011 & 7 & 0 \\
\hline IRN - Iran, Islamic Rep. & 2006 & 2011 & 2 & 0 \\
\hline IRQ - Iraq & 1997 & 2012 & 3 & 0 \\
\hline ISL - Iceland & 2004 & 2008 & 5 & 0 \\
\hline ITA - Italy & 2001 & 2011 & 7 & 0 \\
\hline
\end{tabular}




\begin{tabular}{|c|c|c|c|c|}
\hline JOR - Jordan & 2000 & 2014 & 14 & 0 \\
\hline KEN - Kenya & 1999 & 2005 & 2 & 0 \\
\hline KGZ - Kyrgyz Republic & 1999 & 2011 & 2 & 0 \\
\hline KHM - Cambodia & 1997 & 2012 & 8 & 0 \\
\hline LBN - Lebanon & 2004 & 2011 & 2 & 0 \\
\hline LBR - Liberia & 2008 & 2014 & 3 & 0 \\
\hline LKA - Sri Lanka & 1992 & 2014 & 20 & 0 \\
\hline LSO - Lesotho & 2002 & 2010 & 3 & 0 \\
\hline LTU - Lithuania & 2003 & 2008 & 6 & 0 \\
\hline LUX - Luxembourg & 2004 & 2011 & 8 & 0 \\
\hline LVA - Latvia & 2005 & 2008 & 4 & 0 \\
\hline MDA - Moldova & 1998 & 2014 & 16 & 0 \\
\hline MDG - Madagascar & 2001 & 2012 & 3 & 0 \\
\hline MDV - Maldives & 1998 & 2009 & 4 & 0 \\
\hline MMR - Myanmar & 2005 & 2010 & 2 & 0 \\
\hline MNE - Montenegro & 2006 & 2010 & 2 & 0 \\
\hline MNG - Mongolia & 2000 & 2011 & 7 & 0 \\
\hline MOZ - Mozambique & 1996 & 2014 & 4 & 0 \\
\hline MRT - Mauritania & 2004 & 2014 & 3 & 0 \\
\hline MUS - Mauritius & 1999 & 2012 & 13 & 0 \\
\hline NAM - Namibia & 1993 & 2014 & 6 & 0 \\
\hline NER - Niger & 2007 & 2014 & 3 & 0 \\
\hline NGA - Nigeria & 1993 & 2012 & 6 & 0 \\
\hline NLD - Netherlands & 2001 & 2011 & 7 & 0 \\
\hline NOR - Norway & 2004 & 2008 & 5 & 0 \\
\hline NPL - Nepal & 1995 & 2010 & 5 & 0 \\
\hline PER - Peru & 1993 & 2014 & 19 & 0 \\
\hline PHL - Philippines & 1997 & 2014 & 15 & 0 \\
\hline
\end{tabular}




\begin{tabular}{|c|c|c|c|c|c|}
\hline POL - Poland & 1997 & 2011 & 14 & 0 & 14 \\
\hline PSE - West Bank and Gaza & 1997 & 2008 & 12 & 0 & 12 \\
\hline ROU - Romania & 1992 & 2013 & 12 & 0 & 12 \\
\hline RUS - Russian Federation & 2004 & 2009 & 5 & 0 & 5 \\
\hline RWA - Rwanda & 2002 & 2013 & 3 & 0 & 3 \\
\hline SLE - Sierra Leone & 2003 & 2014 & 2 & 0 & 2 \\
\hline SLV - El Salvador & 1991 & 2014 & 16 & 0 & 16 \\
\hline SVK - Slovak Republic & 2005 & 2008 & 4 & 0 & 4 \\
\hline SVN - Slovenia & 2002 & 2011 & 10 & 0 & 10 \\
\hline SWE - Sweden & 2004 & 2011 & 8 & 0 & 8 \\
\hline SWZ - Swaziland & 1995 & 2000 & 2 & 0 & 2 \\
\hline SYC - Seychelles & 2006 & 2013 & 2 & 0 & 2 \\
\hline SYR - Syrian Arab Republic & 1997 & 2003 & 2 & 0 & 2 \\
\hline TJK - Tajikistan & 1999 & 2009 & 3 & 0 & 3 \\
\hline TUN - Tunisia & 1997 & 2011 & 5 & 0 & 5 \\
\hline TZA - Tanzania & 2000 & 2014 & 7 & 0 & 7 \\
\hline UGA - Uganda & 1999 & 2012 & 5 & 0 & 5 \\
\hline UZB - Uzbekistan & 2000 & 2003 & 3 & 0 & 3 \\
\hline VNM - Vietnam & 1997 & 2010 & 8 & 0 & 8 \\
\hline YEM - Yemen, Rep. & 1998 & 2005 & 2 & 0 & 2 \\
\hline ZAF - South Africa & 1995 & 2014 & 12 & 0 & 12 \\
\hline ZWE - Zimbabwe & 2001 & 2011 & 3 & 0 & 3 \\
\hline TOTAL & 1964 & 2014 & 486 & 2 & 484 \\
\hline
\end{tabular}




\section{B Description of ISCO major groups}

1. Legislators, senior officials and managers: This major group includes occupations whose main tasks consist of determining and formulating government policies, as well as laws and public regulations, overseeing their implementation, representing governments and acting on their behalf, or planning, directing and coordinating the policies and activities of enterprises and organisations, or departments. Reference to skill level has not been made in defining the scope of this major group, which has been divided into three sub-major groups, eight minor groups and 33 unit groups, reflecting differences in tasks associated with different areas of authority and different types of enterprises and organisations.

2. Professionals: This major group includes occupations whose main tasks require a high level of professional knowledge and experience in the fields of physical and life sciences, or social sciences and humanities. The main tasks consist of increasing the existing stock of knowledge, applying scientific and artistic concepts and theories to the solution of problems, and teaching about the foregoing in a systematic manner. Most occupations in this major group require skills at the fourth ISCO skill level. This major group has been divided into four sub-major groups, 18 minor groups and 55 unit groups, reflecting differences in tasks associated with different fields of knowledge and specialisation.

3. Technicians and associate professionals: This major group includes occupations whose main tasks require technical knowledge and experience in one or more fields of physical and life sciences, or social sciences and humanities. The main tasks consist of carrying out technical work connected with the application of concepts and operational methods in the above-mentioned fields, and in teaching at certain educational levels. Most occupations in this major group require skills at the third ISCO skill level. This major group has been divided into four sub-major groups, 21 minor groups and 73 unit groups, reflecting differences in tasks associated with different fields of knowledge and specialisation.

4. Clerks: This major group includes occupations whose main tasks require the knowledge and experience necessary to organise, store, compute and retrieve information. The main tasks consist of performing secretarial duties, operating word processors and other office machines, recording and computing numerical data, and performing a number of customer-oriented clerical duties, mostly in connection with 
mail services, money-handling operations and appointments. Most occupations in this major group require skills at the second ISCO skill level. This major group has been divided into two sub-major groups, seven minor groups and 23 unit groups, reflecting differences in tasks associated with different areas of specialisation.

5. Service workers and shop and market sales workers: (omitted)

\section{Skilled agricultural and fishery workers: (omitted)}

7. Craft and related trades workers: This major group includes occupations whose tasks require the knowledge and experience of skilled trades or handicrafts which, among other things, involves an understanding of materials and tools to be used, as well as of all stages of the production process, including the characteristics and the intended use of the final product. The main tasks consist of extracting raw materials, constructing buildings and other structures and making various products as well as handicraft goods. Most occupations in this major group require skills at the second ISCO skill level. This major group has been divided into four sub-major groups, 16 minor groups and 70 unit groups, reflecting differences in tasks associated with different areas of specialisation.

8. Plant and machine operators and assemblers: This major group includes occupations whose main tasks require the knowledge and experience necessary to operate and monitor large scale, and often highly automated, industrial machinery and equipment. The main tasks consist of operating and monitoring mining, processing and production machinery and equipment, as well as driving vehicles and driving and operating mobile plant, or assembling products from component parts. Most occupations in this major group require skills at the second ISCO skill level. This major group has been divided into three sub-major groups, 20 minor groups and 70 unit groups, reflecting differences in tasks associated with different areas of specialisation.

9. Elementary occupations: This major group covers occupations which require the knowledge and experience necessary to perform mostly simple and routine tasks, involving the use of hand-held tools and in some cases considerable physical effort, and, with few exceptions, only limited personal initiative or judgement. The main tasks consist of selling goods in streets, doorkeeping and property watching, 
as well as cleaning, washing, pressing, and working as labourers in the fields of mining, agriculture and fishing, construction and manufacturing. Most occupations in this major group require skills at the first ISCO skill level. This major group has been divided into three sub-major groups, ten minor groups and 25 unit groups, reflecting differences in tasks associated with different areas of work.

Source: ILO 


\section{Appendix Tables and Figures}

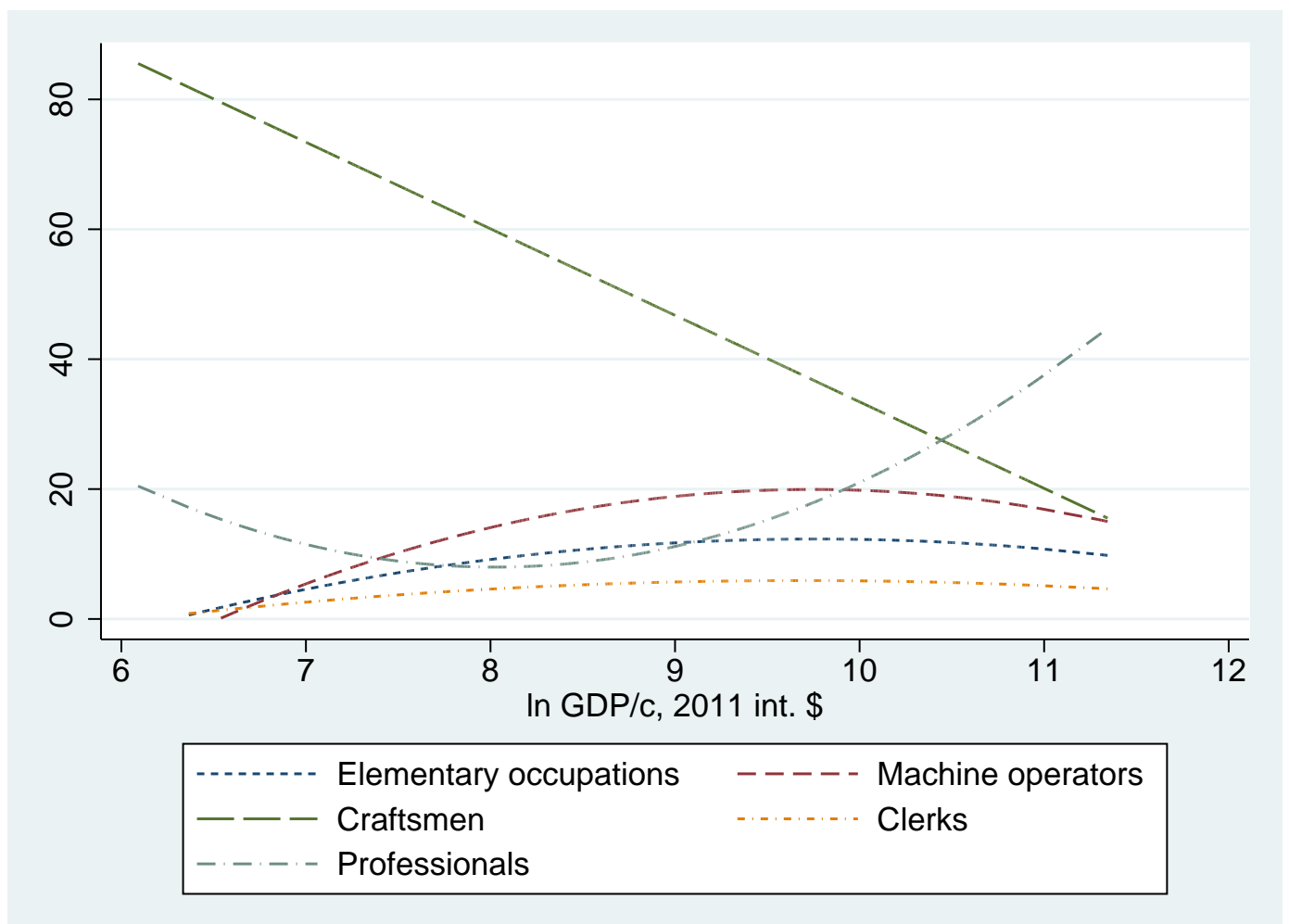

Figure C.1: Simulated employment within manufacturing, by occupation (percentage points) The Figure corresponds to Figure 2 in the main text- with the difference that the dependent variable in the regression is the occupational employment shares within manufacturing. 


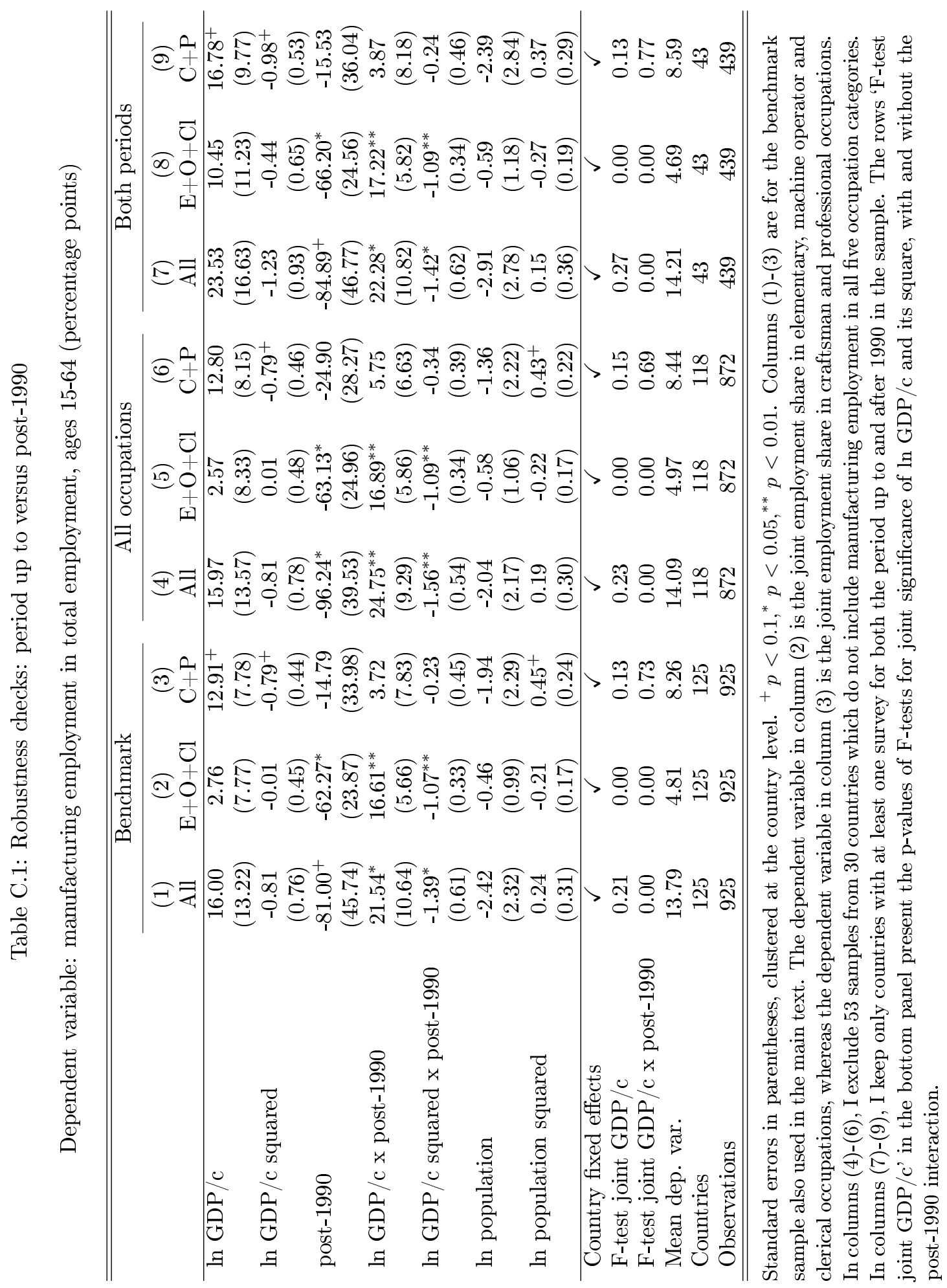




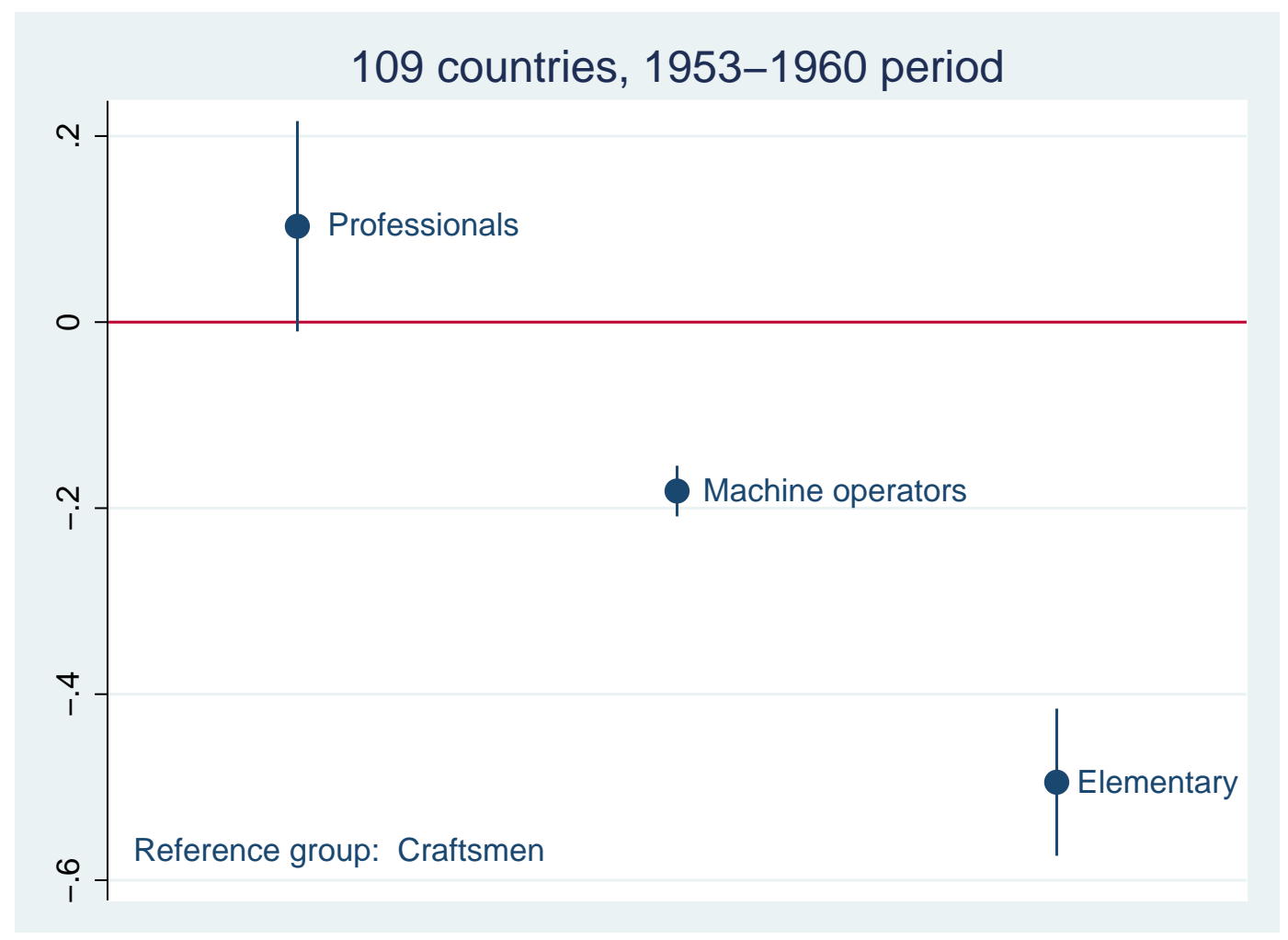

Figure C.2: Occupational wage premia in manufacturing in the 1950s (in log points)

Source: the extended 'Occupational Wages Around the World' (OWW) database as described by Freeman and Oostendorp (2020). The Figure plots the average deviations of manufacturing wages in the respective major group from craftsman wages, in a sample of 109 countries between 1953-1960, along with the 95 percent confidence intervals. Coefficients are obtained from a regression of 8,258 average annual log wages from 24 manufacturing occupations that belonging to one of the 4 occupation groups on country-year dummies and major group dummies. The sample does not include wages from clerical occupations. See Kunst (2019) for an analyses of trends in occupational wage premia in manufacturing over time. 
Table C.2: Trends in the manufacturing wage premium

Dependent variable: Manufacturing premium in log points

\begin{tabular}{lcc}
\hline \hline & $(1)$ & $(2)$ \\
& Less than primary completed & At least primary completed \\
\hline Trend/10 & $-3.29^{+}$ & -1.58 \\
& $(1.90)$ & $(1.38)$ \\
\hline Country fixed effects & $\checkmark$ & $\checkmark$ \\
Mean dep. var. & 13.24 & -3.05 \\
Countries & 88 & 88 \\
Observations & 601 & 601 \\
\hline \hline
\end{tabular}

The manufacturing premium is calculated as $100 *$ the log ratio of income of those with at most incomplete primary schooling who are employed in manufacturing relative to those who work in a different industry. Wage data are taken from IPUMS and I2D2. Standard errors in parentheses, clustered at the country level. ${ }^{+} p<0.1,^{*} p<0.05,^{* *} p<$ 0.01 .

Table C.3: Trends in the manufacturing wage premium by income group

Dependent variable: Manufacturing premium in log points

\begin{tabular}{lcccc}
\hline \hline & \multicolumn{4}{l}{ Less than primary completed, by income } \\
\cline { 2 - 5 } & $(1)$ & $(2)$ & $(3)$ & $(4)$ \\
& Pooled & Low & Middle & High \\
\hline Trend/10 & $-3.29^{+}$ & -2.53 & $-4.37^{*}$ & -0.11 \\
& $(1.90)$ & $(5.75)$ & $(1.99)$ & $(4.38)$ \\
\hline Country fixed effects & $\checkmark$ & $\checkmark$ & $\checkmark$ & $\checkmark$ \\
Mean dep. var. & 13.24 & 15.41 & 11.14 & 18.48 \\
Countries & 88 & 27 & 46 & 15 \\
Observations & 601 & 143 & 369 & 89 \\
\hline
\end{tabular}

The manufacturing premium is calculated as $100^{*}$ the log ratio of income of those with at most incomplete primary schooling who are employed in manufacturing relative to those who work in a different industry. Wage data are taken from IPUMS and I2D2. Standard errors in parentheses, clustered at the country level. ${ }^{+} p<0.1,{ }^{*} p<0.05,{ }^{* *} p<$ 0.01 . 
Table C.4: Trends in the share of wage employment in manufacturing Dependent variable: Wage employment in manufacturing (\%)

\begin{tabular}{lcccccc}
\hline \hline & $(1)$ & $(2)$ & $(3)$ & $(4)$ & $(5)$ & $(6)$ \\
& All & Elementary & Operators & Craftsmen & Clerks & \begin{tabular}{c} 
Professionals \\
\hline Trend/10
\end{tabular} \\
& 0.47 & -0.61 & $1.57^{+}$ & -0.48 & 0.46 & $0.95^{+}$ \\
& $(0.52)$ & $(0.54)$ & $(0.83)$ & $(0.79)$ & $(0.92)$ & $(0.52)$ \\
\hline Country fixed effects & $\checkmark$ & $\checkmark$ & $\checkmark$ & $\checkmark$ & $\checkmark$ & $\checkmark$ \\
Mean dep. var. & 73.17 & 88.00 & 87.17 & 64.98 & 93.54 & 77.84 \\
Countries & 122 & 122 & 122 & 122 & 122 & 122 \\
Observations & 921 & 915 & 912 & 912 & 899 & 919 \\
\hline \hline
\end{tabular}

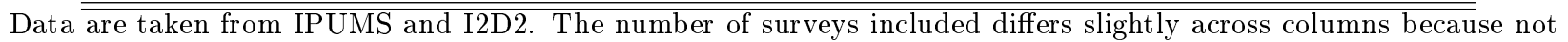
all surveys include manufacturing workers in all occupations. Standard errors in parentheses, clustered at the country level. ${ }^{+} p<0.1,^{*} p<0.05,{ }^{* *} p<0.01$. 


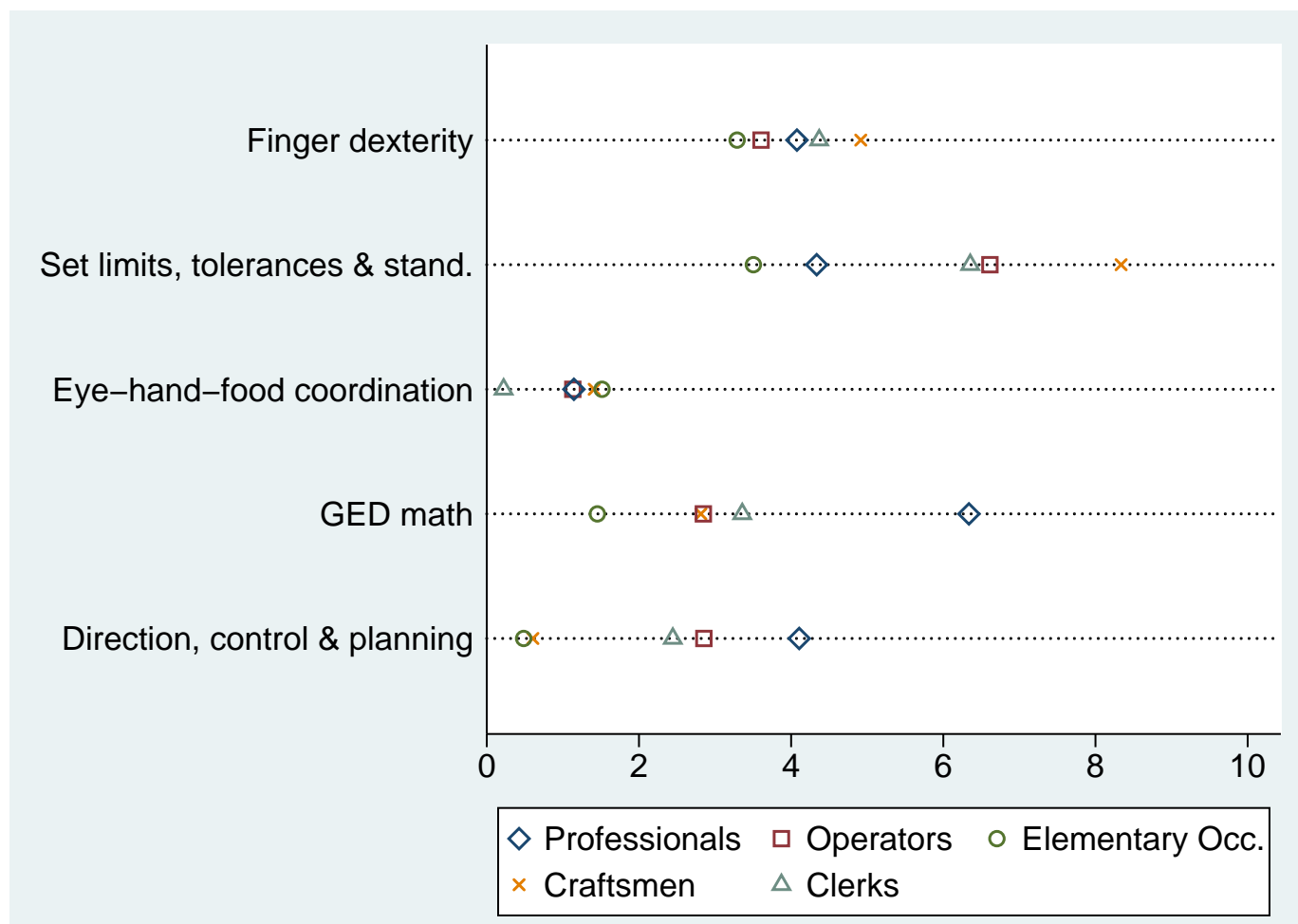

Figure C.3: Task scores by occupation

Task measures come from the 1977 US 'Dictionary of Occupational Titles', and are based on the ranking of occupations in the 1960 distribution of task input in the USA. They range between 0 and 10. See Autor et al. (2003) for a detailed description. I make use of a translation of these US scores into sub-major groups of ISCO-88 by Goos et al. (2014). The figure shows occupation group averages constructed from 11 sub-major groups that are relevant to manufacturing, as indicated by representation among the manufacturing occupations in the extended 'Occupational Wages Around the World' database (and hence, in the ILO 'October Inquiry', which it is based on- see Freeman and Oostendorp (2020) for a description). This excludes major groups 5 ('Service and sales workers') and 6 ('Skilled agricultural, forestry and fishery workers'), as well as some sub-major groups that appear not relevant for manufacturing (for instance, sub-major group 23: 'Teaching Professionals').

The RTI indices of occupations in Figure 5 are calculated from the individual task indices as follows, following Autor et al. (2003): first, they are combined to produce three task aggregates: the Manual task measure corresponds to the DOT variable measuring an occupation's demand for "eye-hand-foot coordination"; the Routine task measure is a simple average of two DOT variables, "set limits, tolerances and standards" measuring an occupation's demand for routine cognitive tasks, and "finger dexterity," measuring an occupation's use of routine motor tasks; and the Abstract task measure is the average of two DOT variables: "direction control and planning," measuring managerial and interactive tasks, and "GED Math," measuring mathematical and formal reasoning requirements. Second, the RTI index is constructed from these aggregates as the difference between the log of Routine task score and the sum of the log of Abstract and the log of Manual tasks scores. 

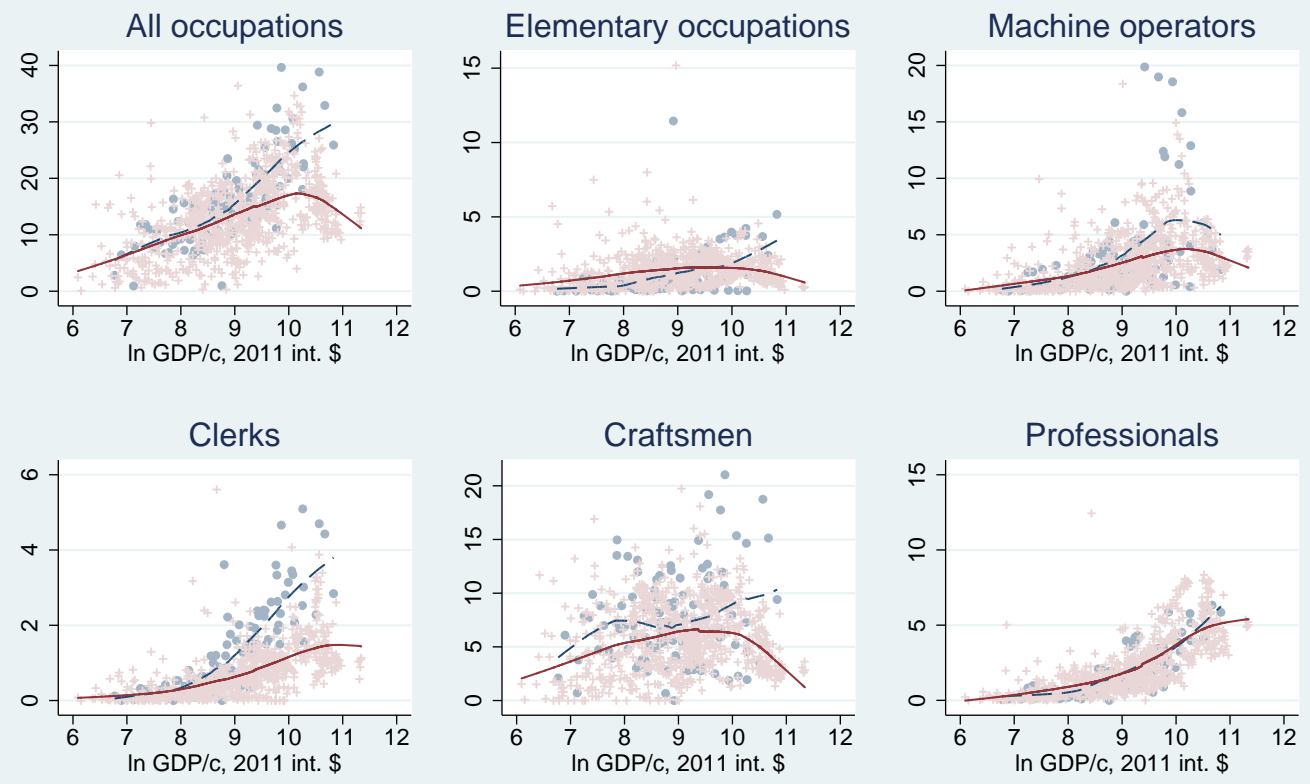

\begin{tabular}{|cl|}
\hline$\quad$ Survey up to 1990 & Survey after 1990 \\
----- Lowess fit & Lowess fit
\end{tabular}

Figure C.4: Manufacturing employment shares by period: raw data and non-parametric fit Every dot represents a survey from a country-year up to or after 1990. Moreover, the Figures include non-parametric estimates of the employment shares by GDP per capita in both periods, produced using the 'lowess' command in Stata, using the default bandwidth. 
Table C.5: Manufacturing employment as a function of income: period up to versus post-1990, by RTI

Dependent variable: manufacturing employment by occupation (percentage points)

\begin{tabular}{lc}
\hline \hline & $(1)$ \\
\hline $\ln$ GDP/c & 0.98 \\
& $(1.67)$ \\
ln GDP/c squared & -0.04 \\
& $(0.10)$ \\
ln GDP/c x RTI & $2.91^{* *}$ \\
& $(0.71)$ \\
ln GDP/c squared x RTI & $-0.17^{* *}$ \\
& $(0.04)$ \\
post-1990 & $-11.01^{+}$ \\
& $(6.09)$ \\
ln GDP/c x post-1990 & $2.83^{*}$ \\
& $(1.41)$ \\
ln GDP/c squared x post-1990 & $-0.18^{*}$ \\
& $(0.08)$ \\
ln GDP/c x RTI x post-1990 & $0.16^{+}$ \\
& $(0.09)$ \\
ln GDP/c squared x RTI x post-1990 & $-0.02^{+}$ \\
& $(0.01)$ \\
\hline Country-occupation fixed effects & $\checkmark$ \\
Population controls & $\checkmark$ \\
F-test joint GDP/c x RTI x post-1990 & 0.10 \\
Mean dependent variable & 1.87 \\
Countries & 125 \\
Observations & 6,475 \\
\hline \hline
\end{tabular}

Standard errors in parentheses, clustered at the country level. ${ }^{+} p<0.1,{ }^{*} p<0.05,{ }^{* *} p<0.01$. The sample corresponds to the one from Table 2 with the difference that it stacks the employment shares in seven occupation groups: 'managers', 'professionals', 'associate professionals', 'clerks', 'craftsman', 'machine operators' and 'elementary occupations'. The number of observations hence results from multiplying the 925 country-years with the 7 occupations. 'RTI' stands for the index of Routine Task Intensity. 'Population controls' in the bottom panel stands for ln population and its square, as well as interactions with the RTI score. The row 'F-test joint GDP/c' presents the p-values of an F-test for joint significance of $\ln$ GDP/c and its square, interacted with the RTI score and a 'post-1990' dummy. 